\title{
Análisis cuantitativo y estudio del fondo mexicano (siglos XVI al XVIII) del Catálogo Colectivo del Patrimonio Bibliográfico Español
}

\author{
José Luis Herrera Morillas \\ Antonio Pulgarín Guerrero *
}

Artículo recibido:

6 de agosto de 2010.

Artículo aceptado:

30 de noviembre de 2010.

\section{RESUMEN}

Se utiliza como fuente de investigación el Catálogo Colectivo del Patrimonio Bibliográfico Español (CCPBE) para localizar y estudiar desde el punto de vista bibliométrico las obras publicados en México durante los siglos XVI, XVII y XVIII conservadas en las bibliotecas españolas. El estudio se centra en analizar los 939 documentos localizados, definiendo la evolución del número de documentos por fecha de publicación, la productividad de los autores, la distribución por lugares de impresión, por impresores, por materias y por idiomas. También indicamos el número de ejemplares que se conservan de cada documento, así como las bibliotecas que los conservan. Por último, realizamos

* Ambos autores pertenecen a la Universidad de Extremadura, Badajoz, España. (José: jlhermor@unex.es); (Antonio: pulgarin@unex.es) 
una búsqueda en el Catálogo de Fondos antiguos de México para comprobar qué libros de los recopilados están incluidos en este Catálogo mexicano y cuáles no.

Palabras clave: Fondo antiguo; Bibliometría; Patrimonio bibliográfico; México; Catálogos colectivos.

\begin{abstract}
Quantitative analysis of sixteenth to eighteenth century mexican book collections listed in the collective catalogue of spanish bibliographic heritage

José Luis Herrera Morillas and Antonio Pulgarín Guerrero

The Collective Catalogue of the Spanish Bibliographic Heritage (CCPBE) is and important source in bibliometric research to locate and study works published in Mexico in the sixteenth, seventeenth and eighteenth centuries, and preserved in Spanish libraries. The study specifically analyzes the 939 books identified and located, providing a definition of the number of documents by year of publication, author productivity, printer, subject matter and language. The number of copies of each document is indicated as is the library holding each copy. These data are cross-checked against the Mexican Rare Books Catalogue to determine coincidences and discrepancies.
\end{abstract}

Key words: Rare book collections; Bibliometrics;

Bibliographic heritage; Mexico; Collective catalog.

\title{
I. INTRODUCCIÓN
}

\subsection{Objetivos y metodología}

El propósito de este trabajo consiste en localizar los documentos antiguos publicados en México durante los siglos XVI al XVIII recogidos en el Catálogo Colectivo del Patrimonio Bibliográfico Español (CCPBE), para realizar un análisis cuantitativo y un estudio en el que se aborda la evolución del número de documentos por fecha de publicación, la productividad de los autores, la distribución por lugares de impresión, por impresores, por materias y por 
idiomas. Indicamos el número de ejemplares que se conservan de cada documento y las bibliotecas que los conservan. También, realizamos una búsqueda en el Catálogo de Fondos antiguos de México para comprobar qué libros de los recopilados están incluidos en este Catálogo mexicano y cuáles no.

En esta investigación partimos de los datos que tiene el Catálogo del Catálogo Colectivo del Patrimonio Bibliográfico Español que es el principal y más eficaz instrumento de control del patrimonio bibliográfico español. Su continua actualización, junto a su fácil acceso a través de la web, permite que la difusión de sus fondos sea rápida y ágil (Reyes, 2003). Este catálogo tiene como objetivo la descripción y localización de los libros y otros fondos bibliográficos pertenecientes a bibliotecas españolas, públicas o privadas, que por su antigüedad, singularidad o riqueza forman parte del Patrimonio Histórico Español, y se realiza en cumplimiento de la Ley 16/1985 del Patrimonio Histórico Español.

El catálogo tiene la gran ventaja de ser colectivo y por tanto una herramienta de gran utilidad, en tanto que da información sobre la existencia de una misma obra en un conjunto de bibliotecas (Velasco y Merlo, 2000). Se trata de un proyecto en fase de desarrollo y está en proceso continuo de ampliación y depuración, que incluye:

- Monografías de los siglos XV-XX (del XX de manera selectiva).

- Manuscritos y otro tipo de materiales (todavía escasos, se incrementarán cuando finalice la catalogación de las bibliotecas españolas).

En la actualidad la mayor parte de los registros describen distintas ediciones de obras impresas entre los siglos XV y XX (hasta 1958), así como los ejemplares concretos de dichas ediciones existentes en las bibliotecas españolas. Se han empezado a incluir también otros materiales bibliográficos (manuscritos, música impresa...).

Según los datos de la última actualización (13 de abril de 2010), el contenido referente a las obras impresas (siglos XV-XX) es el siguiente:

- Registros bibliográficos: 936.525 .

- Registros de ejemplar: 2.679.594.

- Bibliotecas incluidas: 763.

Desde 1997 está accesible en Internet <http://www.mcu.es/bibliotecas/ $\mathrm{MC} / \mathrm{ССРВ/index} \cdot h t m l>$.

La información que nos ofrece es importante y variada, y se refiere tanto a las ediciones como a los ejemplares concretos. La información sobre las ediciones incluye: 
- Autor o autores y otros responsables (impresor, etc.).

- Título (se mantiene como aparece en la portada).

- Datos de edición.

- Datos de publicación (país/localidad, editor, impresor y fecha).

- Lengua del texto.

- Descripción física (hojas o páginas, ilustraciones, formato).

- Series editoriales.

- Notas, incluidas las signaturas tipográficas.

- Materias.

La información sobre los ejemplares abarca:

- Comunidad autónoma (orden alfabético).

- Localidad.

- Biblioteca.

- Signatura topográfica.

- Datos característicos.

- Estado de conservación.

- Encuadernación.

- Procedencia.

- Exlibris.

- Etcétera.

Los campos de la pantalla de búsqueda en la base de datos, que se corresponden en parte con la información sobre las ediciones, son los siguientes:

- Nombre de la persona o entidad (autor).

- Título.

- Lugar de publicación.

- Impresor o editor.

- Fecha de impresión.

- Materia.

- Lengua.

De esta colección de libros seleccionamos para nuestro estudio las obras de los siglos XVI al XVIII, que constituyen en sentido estricto el fondo antiguo -objeto de este trabajo-, dejando para una segunda fase el estudio de los libros del siglo XIX.

A partir de la información sobre los documentos seleccionados elaboramos una serie de tablas para agrupar los datos y facilitar su estudio (autores, 
impresores, lugares de publicación, años de publicación, materias, idiomas, número de ejemplares conservados, bibliotecas propietarias).

También destacamos el trabajo de búsqueda en el Catálogo Colectivo de Fondos Antiguos, Patrimonio Bibliográfico Mexicano, <http://132.248.77.3: 8991/F/-/ ?func=login\&local_base $=$ cfa01 $>$ para comprobar qué obras de las localizadas en el CCPBE están presentes y cuáles no. Este Catálogo mexicano pretende ser una herramienta colectiva bajo la responsabilidad de la Biblioteca Nacional de México (Brito, 2010). Es un proyecto cultural de alcance nacional orientado a la descripción y localización de los fondos antiguos pertenecientes a diversas bibliotecas, públicas y privadas, de México, que por su antigüedad, rareza y valor, constituyen el patrimonio bibliográfico. El objetivo es reunir en una base de datos los registros de los impresos antiguos desde la invención de la imprenta hasta 1821, en su primera fase, mediante la descripción y ubicación física de las obras en las bibliotecas o fondos de la República. Las instituciones participantes en la actualidad son 11.

El catálogo permite dos opciones de búsqueda: básica y avanzada. La búsqueda avanzada incluye los siguientes campos: palabras del título, título, autor, biblioteca, año, número del sistema, y todos los campos. La información que nos ofrece de cada documento recuperado es ésta:

- Número del sistema.

- Autor principal.

- Título.

- Edición.

- Área de publicación.

- Lugar.

- Editorial.

- Año.

- Descripción.

- Ver original (en el catálogo de la biblioteca que lo conserva).

- Tema.

Las búsquedas las realizamos a través de Internet utilizando los sitios web de los dos catálogos. ${ }^{1}$ 


\subsection{El contexto cultural. La imprenta en México durante los siglos XVI al XVIII}

Durante la segunda mitad del siglo XVI encontramos una variedad cultural que se puede diferenciar según tres ámbitos: la cultura urbana, las culturas rurales y las culturas marginales. La cultura urbana es la que presenta caracteres hispánicos más acusados. Se proyectó al mundo en su idioma español americano y por medio de su sistema educativo popular, sus universidades, sus libros y sus escritores (Lucena, 1990).

El español de América no fue el único idioma, coexistió con otros como el nahua, el quechua, el aymará, etc. y será influido por ellos. Se crearon numerosas escuelas para la educación básica, y también universidades que se diferencian en dos categorías: oficiales y religiosas. Las primeras eran denominadas también universidades mayores, generales o de estudios generales y fueron sólo dos: la de México y la de Lima, que coincidieron con los dos grandes virreinatos.

Sobre libros y lecturas, estudios como el de Irving (1979) explican que en el siglo XVI se leían las obras más importantes que se publicaban en el mundo, muchas de las cuales llegaron con los conquistadores; por ejemplo, el virrey de México don Antonio de Mendoza llegó a la capital con 200 libros en sus baúles. Como quiera que sea el aumento de exportación de obras desde España se da a partir de la segunda mitad del siglo con el desarrollo de la transformación urbana. También las bibliotecas fueron apareciendo, especialmente en los conventos, en los colegios y en las universidades. Asistimos a un creciente interés por la Historia que hoy denominaríamos indigenista, en el que empiezan a interesarse los religiosos franciscanos de México, entre quienes destaca fray Bernardino de Sahagún. También surge interés por la Literatura, teniendo en la Épica la gran manifestación, enmarcada por el tema de la llegada de los españoles.

La ciudad de México, capital del Virreinato de Nueva España, fue durante la época colonial la ciudad más importante de América, y escenario de la intensa actividad de las órdenes religiosas (franciscanos, dominicos, mercedarios, jesuitas). Esta ciudad será la primera de América en contar con una imprenta, gracias al interés de fray Juan de Zumárraga, primer obispo de México, quien además de conseguir implantarla será el responsable de las primeras publicaciones. El interés por establecer la imprenta está relacionado con el deseo de extender la cultura traída de España y el de poder suministrar los libros necesarios para esta tarea. No existe unanimidad entre los especialistas respecto a quién fue el primer impresor y cuál el primer impreso. Las dudas giran entre los nombres de Esteban Martín, Juan de Estrada y Juan Pablos (Fernández, 2001). 
Durante el siglo XVII la cultura indígena y la española, tras un siglo de convivencia, van ascendiendo paulatinamente hacia una mayor confluencia. Hay que destacar el papel que juega aquí la enseñanza básica centrada en el aprendizaje de la lectura, la escritura y el cálculo, con el complemento de la doctrina cristiana, para lo cual se usaron como herramientas básicas las "cartillas". Respecto a los estudios superiores asistimos en toda América a la actividad de las órdenes religiosas, que abren y mantienen sus propios centros. Así, en 1621 se le da la primera concesión a la Compañía de Jesús.

Entre las figuras célebres de ese siglo hay que destacar a Juan de Palafox y Mendoza (1600-59) magistrado, obispo, predicador y escritor. Es también muy abundante y de todo tipo la producción poética, como ejemplo citamos a Bernardo de Balbuena, quien nacido en Valdepeñas pasa muy joven a México y gana una serie de premios en distintos certámenes y concursos; en 1602 escribe la Grandeza Mexicana, un canto a México. También recordamos en el campo de la Filosofía, al jesuita Antonio Rubio, autor de la famosa Lógica mexicana.

Respecto a la imprenta, alcanza en ese entonces su máximo esplendor. Sáenz de Santa María (1990), comentando los datos del bibliógrafo chileno J.T. Medina, mantiene que las fechas de las portadas de los libros indican un máximo de 7 anuales en 1684, y un mínimo de 2 en 6 años (1600, 1616, 1670 a 1673); 4 es entonces la cantidad que se repite con mayor frecuencia en los distintos años y resultan al mismo tiempo media y modal. Existe, por lo tanto, una cierta uniformidad en la actividad tipográfica del siglo XVII: los talleres abiertos nunca pasaron de 7 ni bajaron de 2 .

Durante la primera mitad del siglo XVIII los cambios no son muy significativos, poco a poco van entrando nuevas tendencias a través de los libros, tanto franceses como españoles, que responden a las nuevas modas y corrientes de pensamiento, todo ello impulsado por el desarrollo del comercio librero, fruto del crecimiento demográfico y de los lectores, así como de la nueva realidad económica. Este comercio entre España y América siempre tuvo ciertas ventajas en relación con el de otros productos: Madrid, Cádiz y Sevilla eran las ciudades que prácticamente lo controlaban, y aunque era libre, ciertas personas e instituciones contaron con determinados privilegios respecto de él. La libertad comercial favoreció al libro impreso en la península, pues el de América no podía competir con aquél ni en calidad ni en precio. La producción americana se centró en obras de tipo filológico o religioso en lengua indígena, que podían contar con la supervisión de los autores o de los conocedores de los respectivos idiomas, mientras que los libros científicos o literarios procedían casi en su totalidad de España.

En el XVIII aumenta el interés por las ciencias, por la investigación del pasado, por las culturas indígenas, etc. Sobre todo surge mayor atracción en torno a los estudios históricos y geográficos. 
En los siglos anteriores, salvo raras excepciones, la mayoría de las obras se debían a la pluma de eclesiásticos, en el XVIII, además de ellos surgen intelectuales laicos, personajes que comienzan a viajar y a conocer Europa, y a interesarse por las nuevas corrientes de pensamiento.

El periodismo tuvo bastante importancia como vehículo difusor de novedades, del que serían precursoras las relaciones históricas por entregas que realizó en México, desde 1693, Carlos de Sigüenza y Góngora, bajo el título de Mercurio Volante. No obstante el primer periódico mexicano fue La Gaceta de México y noticias de Nueva España, que comenzó a publicarse el 1 de enero de 1722 y tuvo escasa duración debido a las críticas recibidas; y a la que siguieron otros periódicos de mayor éxito como La Gaceta mexicana (Mora, 1990).

Sobre la enseñanza en el nivel primario, a las tradicionales enseñanzas de leer, escribir y contar, poco a poco a lo largo de esta centuria, se irá introduciendo la enseñanza de la Gramática y la Ortografía. Respecto a los estudios universitarios, mediado el siglo, México cuenta con tres de estos centros en México capital, Mérida, Yucatán y Guadalajara.

Por lo que respecta a la imprenta, hacia fines del siglo XVIII ven la luz en México "las imprentillas", expresión que hace referencia a los mal dotados talleres que editaban materiales de poca entidad como hojas y pequeños opúsculos. No obstante después de México habrá que esperar más de 100 años para ver imprentas en otras ciudades, lo cual puede indicar que no había demanda ni necesidad, pero al aumentar la población también surgirá una mayor demanda de impresos y aparecerá la imprenta en otras ciudades como Puebla de los Ángeles, 1640; Oaxaca, 1720; Guadalajara, 1792; Veracruz, 1794; y Mérida, Yucatán, 1813 (Fernández, 1977 y 2001).

\section{Resultados y Discusión}

\subsection{Evolución del número de documentos por siglos (XVI-XVIII)}

\section{Siglo XVI}

El número de documentos localizados en el Catálogo Colectivo del Patrimonio Bibliográfico Español, fechados en este siglo XVI, es de 34 y se desmenuza con 27 libros, 5 folletos y 2 cartas manuscritas. De ellos, 10 libros y 1 folleto están recogidos, también, en el Catálogo de Fondos Antiguos de México.

La Figura 1 muestra los 34 documentos distribuidos por decenios, entre los que destaca el periodo de 1570 a 1579 con 11 documentos, seguido del que se dio de 1550 a 1559 con 8 documentos. 


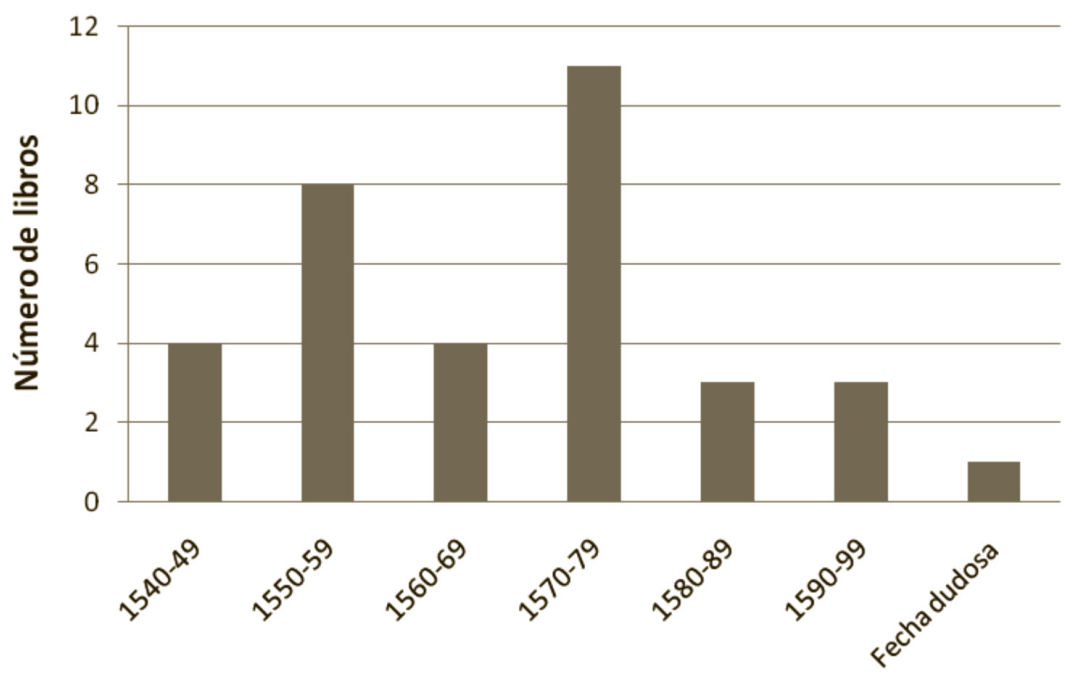

Evolución por decenios

Fig. 1:Evolución del número de libros en el siglo XVI

Los historiadores indican que en la actualidad se han localizado unos 200 títulos impresos en este siglo, ${ }^{2}$ lógicamente sin tener en cuenta los que se han perdido (Castañeda, 2001).

Durante este periodo los impresos casi siempre fueron realizados por religiosos (dominicos, franciscanos, y jesuitas). En la mayor parte de los casos se trató de obras de enseñanza de las lenguas indígenas para ser utilizadas por los mismos religiosos: vocabularios, diccionarios, artes (conjunto de preceptos y reglas para hacer bien algo), o bien obras bilingües de adoctrinamiento empleadas por los mismos religiosos o dirigidas directamente a los indios. Se imprimieron también obras destinadas a la enseñanza que se impartía en sus colegios. Desde el punto de vista lingüístico los textos evidencian el proceso de fijación del idioma, al que asiste España en el siglo XVI, y que se refleja en la imprecisión en el uso de formas ortográficas y grafías, en la castellanización de nombres propios y en la traducción de apellidos extranjeros, etc. (Fernández, 1977).

2 Los datos varían según los estudiosos y las fechas de sus investigaciones; así Medina (1911) describe 174; y la nueva edición de la obra de García Icazbalceta, realizada por Millares Carlo (1954), indica la existencia de 174; o el trabajo de Fernández de Zamora (2009) abarca 131 títulos libros y originales de folletos que se conservan en bibliotecas mexicanas y extranjeras. 


\section{Siglo XVII}

El número de documentos localizados en el Catálogo Colectivo del Patrimonio Bibliográfico Español fechados en este siglo, es de 288, que se corresponden con 151 libros y 137 folletos. De ellos, 64 libros y 6 folletos están recogidos, también en el Catálogo de Fondos Antiguos de México.

En la Figura 2 se muestran los 288 documentos distribuidos por decenios; y se refleja una mayor producción a partir de la segunda mitad de ese siglo.

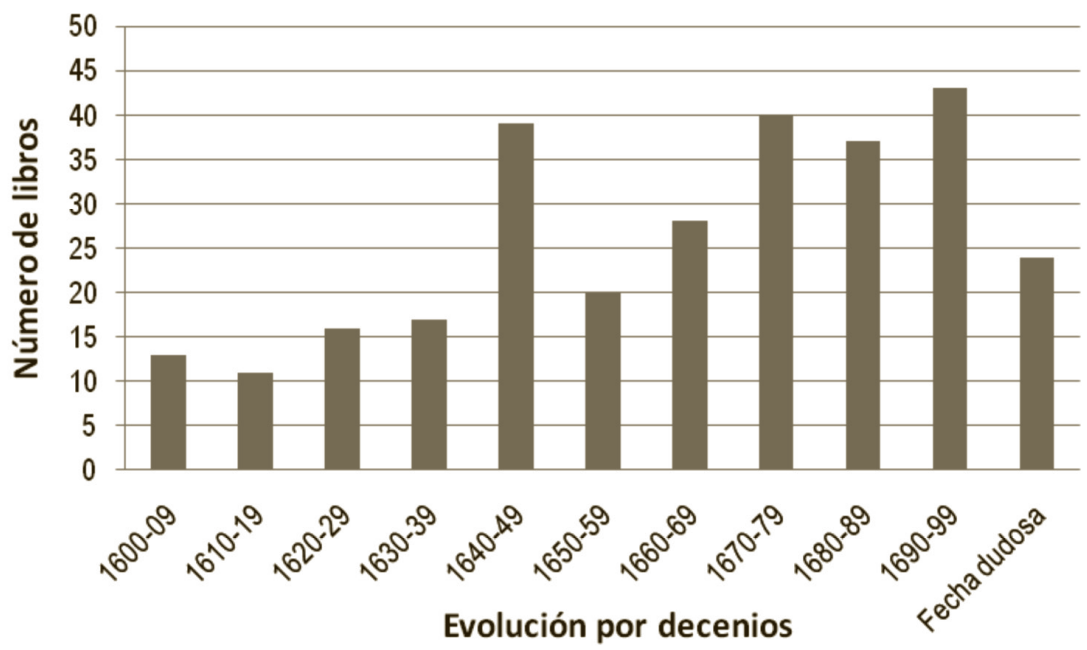

Fig. 2: Evolución del número de libros en el siglo XVII

Entre los historiadores del libro se dan cifras variadas sobre los libros impresos en la Ciudad de México durante ese siglo, por ejemplo, 1228 (Andrade, 1899) o 1869 (Medina, 1909). Durante el XVII creció en forma notoria el número de imprentas y se puso de manifiesto una mayor calidad en las obras. Su temática es muy similar a la del siglo XVI, pero se incrementan los estudios lingüísticos; surgen las crónicas de Indias redactadas por religiosos, que sirven con posterioridad como interesantes fuentes sobre datos históricos, geográficos, etc.; se escriben obras científicas, filosóficas, de astronomía, reseñas de proclamaciones y juras reales, de autos de fe, de entradas de virreyes, de dedicaciones de templos y festividades religiosas y profanas, etc. Las obras de esta época presentan las mismas características tipográficas que las del siglo anterior (Fernández, 1977). 
El número de documentos localizados en el Catálogo Colectivo del Patrimonio Bibliográfico Español, fechados en este siglo fue de 617: 343 libros, 271 folletos y 3 hojas sueltas. De ellos, 167 libros y 15 folletos están recogidos, igualmente, en el Catálogo de Fondos Antiguos de México.

La Figura 3 muestra los 617 documentos distribuidos por decenios. Se alcanzó la máxima producción hacia la mitad del siglo, pues en el periodo de 1750-1759 se consiguen los máximos valores con 96 documentos.

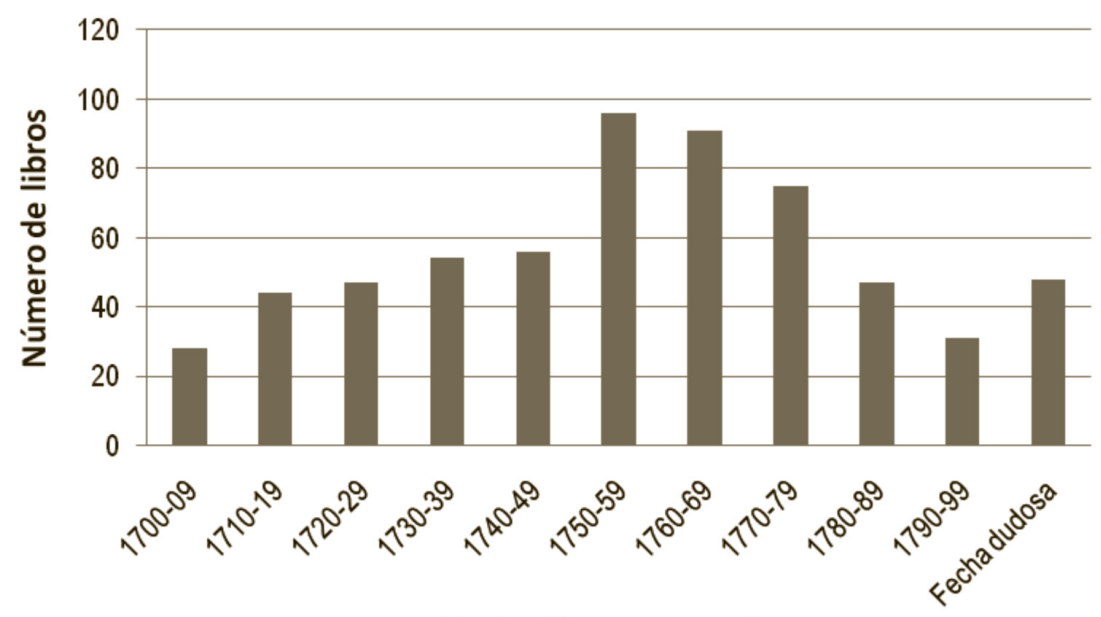

Evolución por decenios

Fig. 3: Evolución del número de libros en el siglo XVIII

El cómputo global de obras salidas de las prensas para este siglo varía según los autores entre 3481 (Martínez, 1987) y 7400 (Medina, 1909).

Estos datos revelan que en ese entonces la producción fue aún más voluminosa y también, como veremos, más variada:

Incorporándose a los temas especificados anteriormente otros que contribuyeron al auge intelectual de la Nueva España y a hacer conocer su historia, sus antigüedades, sus riquezas naturales, su literatura (Fernández, 1977).

La producción impresa del siglo XVIII presenta una continuidad con los dos siglos anteriores: obras de temática religiosa para la instrucción y la piedad; obras para la enseñanza de las lenguas indígenas; crónicas de convento, y obras de Literatura, Historia y Filosofía. Según Martínez (1987), la novedad del siglo fueron las gacetas noticiosas que comenzaron a publicarse 
regularmente en la mayor parte de las ciudades, con noticias de la corte española y de Europa, así como del Virreinato y de la ciudad de México; informes de la llegada y salida de las flotas; bandos municipales; avisos sobre personas u objetos perdidos; fallecimientos; festividades religiosas; vida universitaria; consejos prácticos y pequeños editoriales moralizantes.

\subsection{Distribución de los documentos por autores}

Siglo XVI

De los 34 documentos de este siglo, 31 pertenecen a 22 autores personales. De 3 de estas obras no se indica expresamente el nombre del autor. Los autores más productivos fueron:

- Alonso de Molina: 8 documentos.

- Alonso de la Vera Cruz: 3 documentos.

- Denis le Chartreux: 2 documentos.

- Diego García de Palacio: 2 documentos.

Estos personajes gozaron de gran predicamento, Fray Alonso de Molina, originario de Extremadura, llegó a México en 1522 con sus padres siendo un niño de poca edad, situación que le permitirá aprender con facilidad la lengua indígena. En 1528 ingresa en el convento de San Francisco de la Ciudad de México y se dedicará a la enseñanza de la lengua náhuatl, de la que será un estudioso. Según Medina (1909), Molina sirvió de intérprete a los frailes, pero también destacará en la predicación y en la redacción de libros. El diccionario llamado Vocabulario en Lengua Castellana y Mexicana, escrito entre 1555 a 1571 está considerado como su principal contribución (en el CCPBE edición de Antonio de Espinosa, 1571). Más tarde incluiría el diccionario español-náhuatl, primer diccionario impreso en este continente y el primer acercamiento sistemático a un idioma indígena.

Fray Alonso de la Vera Cruz, nació en Caspueñas (Guadalajara, España) en 1507, y murió en la Ciudad de México en 1584. Al ingresar en la orden de los agustinos cambia su apellido de Gutiérrez por el de Vera Cruz. Aprendió la lengua tarasca y distribuyó entre los conventos de su orden gran cantidad de libros que trajo de España (Fernández, 2001). Destacó por su amplia cultura y mostró sus dotes pedagógicas en sus tres obras filosóficas: Recognitio summularum, 1554; Dialectica resolutio 1554 (en el CCPBE edición de Juan Pablos, 1554) y Physica speculatio, 1557 (en el CCPBE edición de Pablos, 1557) que integraron un curso completo de Artes (Filosofía). 
Diego García de Palacio, originario de Santander (España), siguió durante algún tiempo los estudios de marino, y destacó como ingeniero naval, aunque también se dedicó a la carrera de leyes y ocupó cargos en los gobiernos de la Nueva España. Entre sus libros sobresalen Diálogos militares... escrito con la intención de ayudar al buen uso de la navegación y el cual incluía advertencias útiles para "los mareantes" (en el CCPBE edición de Pedro Ocharte, 1583). Y sobre todo Instrucción náutica... primer libro de construcción naval editado en el mundo (en el CCPBE edición de Pedro Ocharte, 1587).

Otros 18 autores personales están representados con 1 sola obra: Bartolomé de Ledesma, Bernardino de Sahagún, San Buenaventura, Juan de Cárdenas, Juan Díez Freyle, Agustín Farfán, Jean de Gerson, Juan de la Anunciación, Francesco Maurolico, Antonio de Mendoza, Andrés de Moguer, Francisco de Pareja, Pedro de Feria, Vasco de Puga, Luis Velasco y Ruiz de Alarcón, Pedro de Córdoba, Juan de Zumárraga, Domingo de Betanzos (estos 3 últimos como coautores).

\section{Siglo XVII}

De los 288 documentos, 248 corresponden a autores individuales y 16 documentos a autores corporativos (colegios, corporaciones, franciscanos, Archidiócesis de México, Diócesis de Puebla de los Ángeles, universidad, etc.). Existen 24 documentos sin autor expreso. Los autores individuales son 186, de los cuales 157 han publicado sólo 1 obra y 292 o más obras; y son los siguientes:

- Juan de Palafox y Mendoza, Obispo: 9 documentos.

- Juan Francisco de Montemayor y Córdoba de Cuenca: 7 documentos.

- Pedro de Avendaño Suares de Sousa: 6 documentos.

- Agustín de Betancourt (O.F.M.): 6 documentos.

- Isidro Sariñana y Cuenca, Obispo: 6 documentos.

- Francisco de Florencia (S.I.): 5 documentos.

- Carlos de Sigüenza y Góngora: 5 documentos.

- Juan de San Miguel (S.I.): 3 documentos.

- Baltasar de Medina (O.F.M.): 3 documentos.

- Isidro Sariñana: 3 documentos.

- Francisco de Aguíar y Seijas, Arzobispo de México: 2 documentos.

- Esteban de Aguilar: 2 documentos.

- Prepósito Alonso Ramos (S.I.): 2 documentos.

- Pedro de Arenas: 2 documentos.

- Bernardo de Balbuena: 2 documentos. 
- Juan Calderón: 2 documentos.

- Miguel de Castilla (S.I.): 2 documentos.

- Fernando de Cepeda: 2 documentos.

- Juan Díaz de Arce, Arzobispo de Santo Domingo: 2 documentos.

- Antonio de Ezcaray (O.F.M.): 2 documentos.

- Luis Gómez de Solís (O.P.): 2 documentos.

- Grijalva, Juan de (O.E.S.A.): 2 documentos.

- Jerónimo Moreno (O.P.): 2 documentos.

- Antonio de Morg: 2 documentos.

- Julián de Pedraza (S.I.): 2 documentos.

- Guillermo de los Ríos (S.I.): 2 documentos.

- Miguel Sánchez: 2 documentos.

- Francisco de Torres (O.P.): 2 documentos.

- José Vidal (S.I.): 2 documentos.

De entre los anteriores autores, los más productivos y que destacan por su celebridad son:

Juan de Palafox y Mendoza, nacido en 1600 en (Fitero, España) y fallecido en 1659 en (Osma, España) fue obispo de Puebla de los Ángeles de 1640 a 1648, y de Burgo de Osma de 1654 a 1659. Desempeñó el cargo de consejero del Consejo Real de Indias entre 1633 y 1653, y ocupó temporalmente el cargo de Virrey de Nueva España, en funciones. Su actividad en Puebla fue variada: fundó el convento de religiosas dominicas de Santa Inés; redactó constituciones para el seminario de San Juan; erigió los colegios de San Pedro (para gramática, retórica y canto llano) y el de San Pablo (para grados académicos) al que dotó de una biblioteca, hoy llamada Palafoxiana; o impulso la actividad musical. Como escritor fue autor sobre todo de obras de carácter ascético, y relacionadas con el gobierno de su diócesis.

Juan Francisco de Montemayor y Córdoba de Cuenca, polifacético personaje que realizó una ardua tarea de recopilación legislativa. Estudió en Huesca (España). En 1642 entró al servicio de la corona al ser nombrado "Juez de Enquestas" en el reino de Aragón. Más tarde accedió al cargo de oidor de su Real Audiencia en la Nueva España, y después de una larga estancia aquí y en Santo Domingo (30 años), regresó a España en 1679. Como jurista llevó a cabo una elaboración legislativa basada en su experiencia y conocimiento de los indígenas, por lo cual su aportación bibliográfica más sobresaliente es de carácter jurídico, en la que destacan las Exevcationes semicentum exdecisionibvs Regiae Chancilleriae Sancti Dominici.., 1667 (en el CCPBE edición de Francisco Rodríguez Lupercio, 1667). El autor presenta 50 "excubaciones" de carácter jurídico-administrativo tomadas de decisiones emitidas por la 
Real Audiencia de Santo Domingo, que constituyen su primera aportación significativa a la línea de investigación que se iniciara en el siglo XVI, de tanta relevancia a lo largo de la centuria barroca, para recuperar, organizar y sistematizar la legislación de Indias. Pero su producción escrita comprende varias publicaciones y manuscritos de diferente índole, como son Pastor Bonus, Dominus Iesus, sacerdos in aeternum... (en el CCPBE edición de Francisco Rodríguez Lupercio, 1676) de índole estrictamente pastoral. Su obra más sobresaliente y que culmina los trabajos del momento sobre compilación y recopilación jurídica de legislación indiana, es Sumarios de las cedulas, ordenes y provisiones reales... (en el CCPBE edición de la Viuda de Bernardo Calderón, 1678). ${ }^{3}$

Francisco de Florencia, sacerdote jesuita, famoso como profesor de Teología y Filosofía. Fue procurador de la provincia jesuítica en México, en $\mathrm{Ma}$ drid y después en Roma. Autor de numerosas obras, las más célebres: Historia de la Provincia de la Compañia de Jesus de Nueva-España... (en el CCPBE edición de Juan José Guillena Carrascoso, 1694) y Menologio de los varones mas señalados de la Compañia de Jesús en Nueva España, Barcelona, 1661.

Carlos de Sigüenza y Góngora, científico, historiador y literato mexicano, nacido en Ciudad de México en 1645. Durante 20 años ocupó el cargo de catedrático de Astrología y Matemáticas. En 1681 escribió el libro Manifiesto filosófico contra los Cometas, en el que intenta separar la superstición de los hechos observables. Ante las críticas de algunos Sigüenza respondió publicando su obra Libra astronómica y philosóphica (en el CCPBE edición de los Herederos de la Viuda de Bernardo Calderón, 1690), donde explica y razona sus planteamientos sobre los cometas según los conocimientos científicos de su tiempo. ${ }^{4}$

\section{Siglo XVIII}

De los 617 documentos de este siglo, 485 corresponden a autores individuales y 48 a corporativos (dominicos, franciscanos, Hospital real, Cabildo catedralicio, Iglesia católica, diócesis, Virreinato, Universidad, etc.). Existen 84 documentos sin autor expreso. De los 335 autores individuales, 272 han publicado sólo 1 obra y 63 han publicado 2 o más, y son los siguientes:

3 Para más información sobre esta autor véase: María Luisa Rodríguez-Sala; Erice, Miguel B. de. Juan Francisco de Montemayor y Córdoba de Cuenca, abogado, oidor y recopilador del siglo XVII [en línea]. [consulta: 1 julio 2010], disponible en: http://www.juridicas.unam.mx/publi$\mathrm{ca} /$ librev/rev/hisder/cont/9/cnt/cnt7.pdf

4 Para más información sobre este autor véase: “José Juan Arrón, Carlos de Sigüenza y Góngora relectura criolla de los 'Infortunios de Alonso Ramírez”, en Thesaurus, 1987, vol. 42, núm 1, pp., 23-46. 
- Francisco Fabián y Fuero, Obispo de Puebla de los Ángeles: 22 documentos.

- Juan Antonio Oviedo (S.I.): 8 documentos.

- Juan Ignacio Castorena y Ursúa: 7 documentos.

- Juan José de Eguiara y Eguren: 7 documentos.

- Francisco de San Cirilo (O.C.D.): 7 documentos.

- Santiago Magro Zurita: 6 documentos.

- José Antonio Alzate y Ramírez: 5 documentos.

- Isidro Félix de Espinosa (O.F.M.): 5 documentos.

- Ángel Maldonado, Obispo de Oaxaca: 5 documentos.

- José Manuel Rodríguez (O.F.M.): 5 documentos.

- Bartolomé Felipe Ita y Parra: 5 documentos

- Pedro Antonio de Aguirre (O.C.D.): 4 documentos.

- Miguel Anselmo Álvarez de Abreu y Valdez, Obispo Antequera (México): 4 documentos.

- Matías de Escobar (O.E.S.A.): 4 documentos.

- Francisco Javier Lazcano (S.I.): 4 documentos.

- Mariano Antonio de la Vega: 4 documentos.

- José Antonio de Villa-Señor y Sánchez: 4 documentos.

- Publio Virgilio Marón: 4 documentos.

- Andrés de Arce y Miranda: 3 documentos.

- José de Arlegui, (O.F.M.): 3 documentos.

- Carballido y Cabueñas, Juan Miguel: 3 documentos

- Francisco de Florencia (S.I) : 3 documentos

- Leonardo Levanto (O.P.) : 3 documentos

- Antonio López Murto (O.F.M.) : 3 documentos

- Antonio Manzilla (O.F.M.) : 3 documentos

- Mendonza, Juan de: 3 documentos

- Juan Vicente de Guemes, Conde de Revilla Gigédo, Virrey de México: 3 documentos

- Gerardo Moro: 3 documentos.

- Nicolás de Jesús María (O.C.D.): 3 documentos.

- Manuel Antonio Valdés: 3 documentos.

- Alfonso Alberto de Velasco: 3 documentos.

- Hermenegildo de Vilaplana (O.F.M.): 3 documentos.

- Juan de Alvarado (O.P.): 2 documentos.

- Francisco Santiago Calderón, Obispo Antequera de Oaxaca: 2 documentos.

- Pedro Camarena y Hernández: 2 documentos.

- José de Castro (O.F.M.): 2 documentos. 
- Pedro de la Concepción y Urtiaga: 2 documentos.

- Manuel Romualdo Dallo y Zavala (O.P.): 2 documentos.

- Melchor de Espínola: 2 documentos.

- José Fernández de Palos: 2 documentos.

- Antonio Manuel de Folgar: 2 documentos.

- José Antonio García de la Vega: 2 documentos.

- Lorenzo Antonio González de la Sancha: 2 documentos.

- Antonio Guillen de Castro: 2 documentos.

- Julián Gutiérrez Dávila (C.O.): 2 documentos.

- Bruno Francisco Larrañaga: 2 documentos.

- José de Larrimbe (O.P.): 2 documentos.

- José Méndez: 2 documentos.

- Francisco Javier Molina (S.I.): 2 documentos.

- Antonio Casimiro de Montenegro (O.P.): 2 documentos.

- Juan José Mariano de Montufar: 2 documentos.

- Miguel Nieto de Almirón: 2 documentos.

- Francisco Palou (O.F.M.): 2 documentos.

- Bernardo Pazuengos: 2 documentos.

- Manuel Pérez (O.S.A.): 2 documentos.

- José Antonio Ponce de León: 2 documentos.

- Jerónimo Ripalda: 2 documentos.

- José Rivera Bernárdez Conde de Santiago de la Laguna: 2 documentos.

- Juan de Sarria y Alderete: 2 documentos.

- Nicolás de Segura (S.I.): 2 documentos.

- Carlos de Tapia Centeno: 2 documentos.

- José Torrubia (O.F.M.): 2 documentos.

- Miguel Venegas, (S.I.): 2 documentos.

De este listado, dentro del grupo de autores con más obras, sobresalen como personajes destacados los siguientes:

Francisco Fabián y Fuero (1773-1794), arzobispo de Puebla de los Ángeles, quien sucedió en el cargo a Juan de Palafox, y continuó su obra. Esta labor pastoral lo llevó a redactar una numerosa documentación, como se refleja en el CCPBE. En 1773 es nombrado arzobispo de Valencia (España). ${ }^{5}$

Juan Ignacio Castorena y Ursúa, se le ha considerado el primer periodista mexicano. Nació en Zacatecas, en 1688 y realizó estudios en el Real Colegio

5 Para más información véase: Francisco Rodríguez de Coro, Fabián y Fuero. Un ilustrado molinés en Puebla de los Ángeles, Madrid: Biblioteca de Autores Cristianos, 1998. 
de San Ildefonso de la Ciudad de México, luego en la Universidad de Ávila (España) se doctoró en Teología. Regresó a México con el nombramiento de Prebendado. Durante 20 años impartió la cátedra de Escritura; fue chantre, inquisidor ordinario, abad de San Pedro, provisor de indios, vicario general de los conventos de religiosas, teólogo de la nunciatura de España, capellán y predicador del rey Carlos II. En 1722 fundó la Gaceta de México y Noticias de Nueva España, primera publicación mensual, de corta duración. En 1729 fue consagrado obispo y ejerció en Yucatán. ${ }^{6}$ Entre sus escritos abundan también los de carácter ascético y religioso como los que hemos localizado en el CCPBE.

Juan José de Eguiara y Eguren, natural de la Ciudad de México (16961763), fue catedrático de la Real y Pontificia Universidad de México y célebre por su sabiduría, sobre todo por su laboriosa obra titulada Bibliotheca Mexicana... (en el CCPBE edición de Typographiâ in aedibus authoris editioni eiusdem Bibliothecae destinata, 1755). Un intento de dar a conocer la producción científica y literaria mexicanas, desde antes de la llegada de los españoles, hasta mediados del siglo XVIII. Pero sólo pudo publicar en vida el tomo I. ${ }^{7}$

José Antonio Alzate y Ramírez nació el 20 de noviembre de 1737 en Ozumba, en la antigua Provincia de Chalco, hoy Estado de México; fue sacerdote, cartógrafo, historiador, naturalista, botánico y periodista. Tuvo de joven vocación por las ciencias exactas como la Física, la Química, las Matemáticas, la Astronomía, las Ciencias naturales, así como por la Filosofía y las Bellas Letras, y sobresalió en el conocimiento de los clásicos latinos. Fue miembro correspondiente de las Academias de Ciencias de Francia y de España, y uno de los primeros observadores de la meteorología mexicana. Perteneció al Real Jardín Botánico de Madrid, y fue distinguido como correspondiente por la Real Academia Española. Escribió sobre Botánica y Zoología, e hizo observaciones científicas. Se dedicó también al estudio de la Flora y de la Agricultura de México.

Empleó muchos años en la observación de los astros y fenómenos meteorológicos, y sus comentarios referentes a la aurora boreal, publicados en 1789 son importantes. Dirigió sus publicaciones periódicas y, como ilustrado que era, escribió multitud de artículos acerca de todos los temas conocidos. ${ }^{8}$

6 Para más información véase: Moisés Ochoa Campos, Reseña Histórica del Periodismo Mexicano, edición conmemorativa del tricentenario del nacimiento de nuestro primer periodista, México: Editorial Porrúa, 1968.

7 Para más información véase: Agustín Millares Carlo, Don Juan José de Eguiara y Eguren (1695. 1763) y su Bibliotheca Mexicana, México: Ediciones Filosofía y Letras, 1957.

8 Para más información véase: Hugo Mendieta Zerón, "La vida de un divulgador de la ciencia: José Antonio Alzate y Ramírez”, en El muégano, 2002, diciembre-enero, pp. 5-7. 


\subsection{Distribución de los documentos por impresores}

Comenzando por el siglo XVI, el número de impresores distintos para los 34 documentos de este siglo fue de 6 impresores. Son los siguientes, ordenados de acuerdo con el volumen de obras localizadas:

- Pedro Ocharte: 9 documentos.

- Juan Pablos: 8 documentos.

- Pedro Balli: 6 documentos.

- Antonio Espinosa: 4 documentos.

- Juan Cromberger: 3 documentos.

- Antonio Ricardo: 2 documentos.

- Sin nombre expreso del impresor: 2 documentos.

Los historiadores de la imprenta nos indican la existencia de únicamente 8 impresores hasta finales del siglo XVI (Medina, 1909), por lo que estos resultados indican una buena representación. A continuación recogemos unos breves datos biográficos de estos impresores y los presentamos en orden cronológico.

- Juan Cromberger (1539-1547): a él se le atribuye la primera imprenta de México, hijo de Jacome Cromberger, impresor alemán establecido en Sevilla desde 1500. Juan comenzó a trabajar con su padre de 1525 a 1527, y más tarde se trasladó a México. Cromberger falleció a mediados de septiembre de 1540.

- Juan Pablos (1539-1560): de origen italiano (Brescia, Lombardía) está vinculado a Juan Cromberger hasta el fallecimiento de éste. El 14 de julio de 1548 adquiere licencia por seis años para establecerse como propietario único del taller. En sus libros emplea con frecuencia caracteres góticos, romanos y la cursiva. En estas ediciones su nombre se indica de modos diferentes: Excudebat Ioannes Paulus Brissenssen; Escudebat Ioannes Paulus Brissenssen agregando a veces la palabra calcographum, o bien Excussum opus Mexici in aedibus Ioannes Pauli Brissenssenssis.

- Antonio Espinosa (1559-1575): originario de Jaén (España). Se sabe que antes de 1558 ya estaba en México; con bastante probabilidad colaboró con Juan Pablos. Obtuvo en septiembre de ese año licencia para establecer una imprenta en México, y en unión de sus hermanos abrió 
su taller a fines de 1559. Su experiencia como cortador de punzones y fundidor de letras le permitió disponer de una riqueza de tipos góticos, romanos, cursivas y notas de canto llano. Es uno de los pocos impresores que utilizó marca de impresor.

- Pedro Ocharte (1563-1592): es el tercer impresor establecido en México, de origen francés, nacido en Rouen. Entra a formar parte de la familia de Juan Pablos -se casó con su hija-. En su taller empleó gran variedad de tipos (a veces dentro de una misma obra) de iniciales y de grabados. Sus impresos traslucen todavía cierta imprecisión ortográfica (periodo de fijación de la lengua castellana) en el empleo de grafías, nombres propios y el uso de mayúsculas.

- Pedro Balli (1574-1600): librero, encuadernador e impresor de origen salmantino, se caracterizó por la edición de textos bilingües, en castellano y lenguas indígenas, especialmente artes, diccionarios y vocabularios.

- Antonio Ricardo (1577-1579): de origen italiano, instaló su taller en el Colegio jesuítico de San Pedro y San Pablo. Luego se traslada a Lima donde introduce la imprenta. Durante el periodo en el que permaneció en México imprimió unas diez obras.

Los 288 documentos del siglo XVII se deben a 37 impresores diferentes (distinguiendo a cada miembro y heredero de una familia o saga de impresores). Hay 60 documentos en los que no aparece expreso el nombre del impresor. Los 37 impresores son los siguientes, ordenados por el volumen de obras localizadas:

- Familia Calderón: 61 documentos (5 Bernardo Calderón, 49 Viuda de Bernardo Calderón, 7 Herederos de la Viuda de Bernardo Calderón).

- Familia Rodríguez Lupercio: 31 documentos (23 Francisco Rodríguez Lupercio, 8 Viuda de Francisco Rodríguez Lupercio).

- Juan Ruiz: 22 documentos.

- Juan José Guillena Carrascoso: 16 documentos.

- Diego Fernández de León: 12 documentos.

- María de Benavides: 10 documentos (2 como Viuda de Juan de Ribera).

- Francisco Salbago: 10 documentos.

- Juan de Ribera: 8 documentos.

- Francisco Robledo: 8 documentos.

- Hipólito de Ribera: 6 documentos.

- Familia López Dávalos: 5 documentos (3 Diego López Dávalos, 2 
Viuda de Diego López Dávalos).

- Enrique Martínez: 5 documentos.

- Juan Blanco Alcázar: 4 documentos.

- Viuda de Juan de Borja y Gandía: 4 documentos.

- Familia Villa Real: 3 documentos (1 Juan Villa Real, 2 Herederos de Juan Villa Real).

- Familia Balli: 6 documentos (2 Pedro Balli, 1 Viuda de Pedro Balli, 3 Jerónimo Balli).

- Juan de Alcázar: 2 documentos.

- Viuda de Diego Garrido: 2 documentos.

- Melchor Ocharte: 2 documentos.

- Diego Pérez de los Ríos: 1 documento.

- Pedro de Quiñones: 1 documento.

- Agustín Santistevan: 1 documento.

- Antonio Calderón Benavides: 1 documento.

- Cornelio Adriano César: 1 documento.

- Diego Gutiérrez: 1 documento.

- Pedro de Charte: 1 documento.

- Juan Chrysostomo: 1 documento.

- Viuda de Francisco Calderón: 1 documento.

- Viuda e hijos de Juan Dorga: 1 documento.

- Fernando Balli: 1 documento.

De todos los impresores 8 superan la decena de libros impresos. ${ }^{10}$ Varios de ellos están incluidos en dos grandes familias de impresores: la familia Calderón y la familia Rodríguez Lupercio. El fundador de la primera es Bernardo Calderón (1631-1641), también librero, era natural de Alcalá de Henares; su producción aumenta sobre todo a partir de 1639. Su viuda (1641-1684), doña Paula Benavides, se hizo cargo de la imprenta y tienda entre los años de 1641 y 1684, y dejó como herederos de la imprenta a sus hijos Diego y María, quienes trabajaron de 1684 a 1718. En ese tiempo María ya estaba casada con Juan de Ribera, impresor, quien por su parte heredó la imprenta de los Calderón a tres de sus hijos: José, Francisco y Miguel de Ribera Calderón. Los herederos de la Viuda de Bernardo Calderón (1684-1703) en 1688 añaden al nombre de sus propietarios el de la "Imprenta de Antuerpiae", que alterna desde el año siguiente con el de "Imprenta Plantiniana". En Julio de 1698 se le llama también "Imprenta del Superior Gobierno"; por tanto, como man-

10 Los datos biográficos los hemos obtenido de las obras de Medina (1909) y Martínez Leal (2002). 
tiene Martínez Leal (2002), estamos ante una saga con una larga tradición tipográfica que perduró a través de su descendencia por 137 años. Bernardo Calderón, su viuda y sus herederos dejaron constancia de su labor en 497 impresos de diferente índole, principalmente con una temática religiosa.

De la segunda familia, el iniciador es Francisco Rodríguez Lupercio (1658-1673) también impresor y librero, familia que sin ser tan extensa como la de los Calderón, fue bastante productiva: en unos 80 años sacaron a la luz cerca de 444 impresos. Casado con Gerónima Delgado, quien lo sustituye tras su muerte en 1683 y hasta 1696, y lleva a cabo más de 80 trabajos de imprenta. En su tienda se podían adquirir, sobre todo, hagiografías, sermones y obras espirituales.

Los otros 3 impresores que destacan de manera individual en nuestro ranking son Juan Ruiz, Juan José Guillena Carrascoso y Diego Fernández de León.

Juan Ruiz (1613-1675): su carrera de impresor parece haberla comenzado como cajista de López Dávalos. Teniendo ya imprenta propia en 1613, Ruiz gozó de la confianza del Santo Oficio, de quien fue impresor hacia el 1667.

Juan José Guillena Carrascoso (1684-1700): el primer emplazamiento de su imprenta estuvo en el Empedradillo, próximo al de doña María de Benavides, la Viuda de Juan de Ribera. Más tarde su imprenta se trasladó y apareció con la designación de "Imprenta nueva". También utilizó el nombre de "Imprenta Plantiniana”. Su trabajo más notable es la Historia de la Provincia de la Compañia de Jesús de Nueva-España del P. Florencia. En 1695 se hizo editor y trajo a luz por su cuenta El confesor instruido, del P. Señeri.

Diego Fernández de León (1690-1692 y 1710): abrió una tienda de libros en Puebla de los Ángeles. En 1688 renovó su material, con tipos de origen holandés, y desde entonces utilizó la expresión de "Plantiniana". Durante un periodo ejerció como tipógrafo en la Casa Profesa de la Compañía de Jesús.

En el siglo XVIII los 617 impresos recopilados responden a 44 impresores diferentes (distinguiendo los distintos miembros y herederos de una familia o saga de impresores). Hay 104 documentos que no tienen el nombre expreso del impresor. Los 44 impresores son los siguientes, ordenados por el volumen de obras localizadas:

- Familia Hogal: 98 documentos (42 José Bernardo de Hogal, 36 Viuda de José Bernardo de Hogal, 2 Herederos de la Viuda de José Bernardo de Hogal, 15 José Antonio de Hogal, 2 José de Hogal, 1 Viuda de José de Hogal).

- Familia Ribera: 86 documentos (3 Viuda de Miguel de Ribera, 21 de Herederos de la viuda Miguel Ribera Calderón, 49 María de Ribera, 
13 Herederos de María de Ribera).

- Felipe de Zúñiga y Ontiveros: 67 documentos.

- Imprenta de la Biblioteca Mexicana: 59 documentos.

- Colegio de San Ildefonso: 41 documentos.

- Familia Jáuregui: 31 documentos (17 José de Jáuregui, 14 Herederos de José de Jáuregui).

- Familia Rodríguez Lupercio: 26 documentos (1 Francisco Rodríguez Lupercio, 25 Herederos de la viuda de Francisco Rodríguez Lupercio).

- Familia Guillena Carrascoso: 21 documentos (1 José Guillena Carrascoso, 1 Herederos de José Guillena Carrascoso, 7 Juan José Guillena Carrascoso, 12 Herederos Juan José de Guillena Carrascoso).

- Viuda de Miguel de Ortega Bonilla: 15 documentos.

- Francisco de Ribera Calderón: 14 documentos.

- Imprenta del Real Seminario Palafoxiano: 12 documentos.

- Colegio Real de San Ignacio (Puebla de los Ángeles): 4 documentos.

- José Fernández Jáuregui: 4 documentos.

- José Rafael Larrañaga: 3 documentos.

- Francisco Javier Morales y Salazar: 3 documentos.

- Juan Francisco de Ortega Bonilla: 3 documentos.

- Herederos de Bernardo Calderón: 2 documentos.

- Calle de la Palma: 2 documentos.

- Diego Fernández de León: 2 documentos.

- Pedro de la Rosa: 2 documentos.

- Francisco Javier Sánchez: 2 documentos.

- José Antonio Alzate y Ramírez: 1 documento.

- Empedraillo: 1 documento.

- María Benavides, Viuda de Juan de Ribera: 1 documento.

- Manuel Espinosa: 1 documento.

- Franchelli: 1 documento.

- Sebastián Guevara y Ríos: 1 documento.

- Imprenta de la calle de San Bernardo: 1 documento.

- Antonio Marín: 1 documento.

- Felipe de Ontiveros: 1 documento.

- Andrés Sánchez: 1 documento.

- Typis Sacrorum Librorum: 1 documento.

- Typographia in aedibus authoris editioni eiusdem Bibliothecae destinata: 1 documento.

- Typographia Regalis, Antiquioris S. Ildefonsi: 1 documento.

- Alejandro Valdés: 1 documento. 
- Antonio Velázquez: 1 documento.

- Herederos del capitán Juan de Villa-Real: 1 documento.

De todos los impresores, 24 superan la decena de libros impresos, de ellos 18 están incluidos en familias de impresores. ${ }^{11}$

- Familia Hogal: José Bernardo de Hogal (1721-1741) fue teniente de caballos en Andalucía. Se trasladó a México en 1720 en una misión profesional, y aquí decidió establecer una imprenta. Solicita y le es concedido en 1727 el título de Impresor mayor de la ciudad. Su Viuda (1741-1755) sigue con el establecimiento y alcanza su apogeo en 1746 cuando publica obras tan notables y voluminosas como el Escudo de armas de México de Cabrera Quintero, las Disertaciones de Eguiara, la Crónica de fray Félix de Espinosa, el Arte maya de Beltrán de Santa Rosa y el Teatro americano de Villaseñor. Sus herederos continuaron a cargo de la imprenta hasta 1766 en que pasó a ser propiedad de don José Antonio de Hogal (1766-1787), hijo de José Bernardo, dedicado a la carrera eclesiástica. Al año siguiente de entrar la imprenta en funciones, obtuvo el título de "Impresor del Superior Gobierno" y su establecimiento se llamó desde entonces "Imprenta Real”, título y cargo que habían estado vinculados hasta entonces a la imprenta de doña María de Ribera y a la de sus herederos.

- Familia Ribera: a ella pertenece Miguel Ribera Calderón (1701-1707) quien era también mercader de libros, hijo de Juan de Ribera y de María Calderón. Le sucede su Viuda (1707-1714), Gertrudis de Escobar y Vera, que continuó a cargo del taller de su esposo en el Empedradillo, hasta que se hicieron cargo sus Herederos (1714-1732). A principios de 1721 renuevan su material y por ello le advierten al público que los trabajos se harían en "Imprenta nueva". En septiembre de ese mismo año se anuncia que la imprenta está a cargo del taller Domingo Sáenz Pablo, familiar del Santo Oficio. Y desde principios de 1727 se la llama "Imprenta Real del Superior Gobierno". María de Ribera Calderón y Benavides (1732-1754) era hija de Miguel de Ribera Calderón y de Gertrudis. Su taller se titula desde el primer momento "Imprenta Real del Superior Gobierno", demostrando con ello que el privilegio de que se valían los herederos de la viuda de Miguel de Ribera Calderón había pasado a ser suyo, a título de miembro de esa familia, e indicando que en ella se hacían los impresos oficiales, y también los 
del "Nuevo Rezado". Los trabajos que produjo son muy numerosos, especialmente en los años 1745 a 1748. Destaca en la composición de obras en latín, como tesis universitarias y añalejos. Sus Herederos (1754-1768) continúan con la Imprenta gozando de los mismos privilegios, seguía designándose como la del "Nuevo Rezado y del Superior Gobierno" y en ocasiones bajo el sólo título de "Imprenta Real". Despojada en 1768 del privilegio real a favor de don José Antonio de Hogal, y de los rezos, que consiguió don José de Jáuregui, hubo de cerrar casi inmediatamente sus puertas.

- Familia Jáuregui: se inicia con José de Jáuregui (1766-1778) al adquirir la imprenta de la Biblioteca mexicana y parece que también la imprenta que había sido de los Herederos de doña María de Ribera. En 1768 obtiene privilegio para imprimir todos los libritos y cuadernos de los estudios menores. Sus Herederos (1778-1796) se hacen cargo de la imprenta que continúa con los títulos de "Biblioteca mexicana y del Nuevo Rezado". A fines de 1781 aparece con la designación de "Imprenta nueva madrileña", circunstancia que puede indicar que su material habría sido enriquecido con una fundición llevada de Madrid, a la que siguió otra de la misma procedencia, que llegó a México en mayo de 1788. Sin duda por esta circunstancia, desde poco después de 1781 comenzaron a llegar trabajos de mayor entidad que los libritos de devoción que habían estado manteniéndola, y las impresiones resultaron también mucho más limpias y esmeradas. Bajo ese pie continuó el taller hasta 1791, en que pasó a figurar como de propiedad del bachiller don José Fernández Jáuregui (1791-1800), que sería probablemente sobrino y uno de sus herederos.

Del resto de impresores, los que están mejor representados en el CCPBE son:

- Felipe de Zúñiga y Ontiveros: hermano de Cristóbal (1761-1764), ambos copropietarios de la Imprenta Antuerpiana hasta 1764, fecha en la que el segundo de los socios se quedó con el taller.

- Imprenta de la Biblioteca mexicana (1753-1767): su fundador y dueño fue Juan José de Eguiara y Eguren, quien solicitó y obtuvo licencia del monarca para llevarla a México, lo cual se lleva a cabo en 1744 y cuyo objetivo inicial fue imprimir la obra de su dueño Biblioteca Mexicana. La posición social e ilustración de su propietario y el hecho de ser imprenta nueva favoreció su prosperidad.

- Colegio de San Ildefonso: esta imprenta establecida en el Colegio Real 
y Más Antiguo de San Ildefonso de México empezó a funcionar a mediados de 1718. En 1755 se hace notar en sus portadas que salían de la "nueva imprenta del Colegio", con lo que se quería indicar sin duda que el establecimiento acababa de emplear por esos días tipos recientemente adquiridos. Hacia 1760 el establecimiento adquirió un auge notable que continuó sus labores hasta 1767 , cuando cesa de funcionar por causa de la expulsión de los jesuitas, a quienes pertenecía el Colegio.

- Viuda de Miguel de Ortega Bonilla: se llamaba Catalina Cerezo y desde 1715 se hace cargo del taller de su marido radicado en Puebla de los Ángeles, donde se estableció tras comprarle a Diego Fernández de León, con el privilegio de que disfrutaba para publicar las Cartillas.

- Francisco de Ribera Calderón (1703-1731): hermano de Miguel, se estableció como impresor hacia junio de 1703; en algunas portadas aparece como impresor del Santo Oficio.

- Imprenta del Real Seminario Palafoxiano: situado en la Puebla de los Ángeles, tiene su origen en la imprenta de los Reales y Pontificios Colegios de San Pedro y San Juan; y anteriormente en la del Real Colegio de San Ignacio, taller iniciado en 1758 montado por los jesuitas y en funcionamiento hasta su expulsión.

En la Figura 4 recogemos de manera conjunta los impresores más productivos de los tres siglos. La elaboración de esta figura nos ha permitido

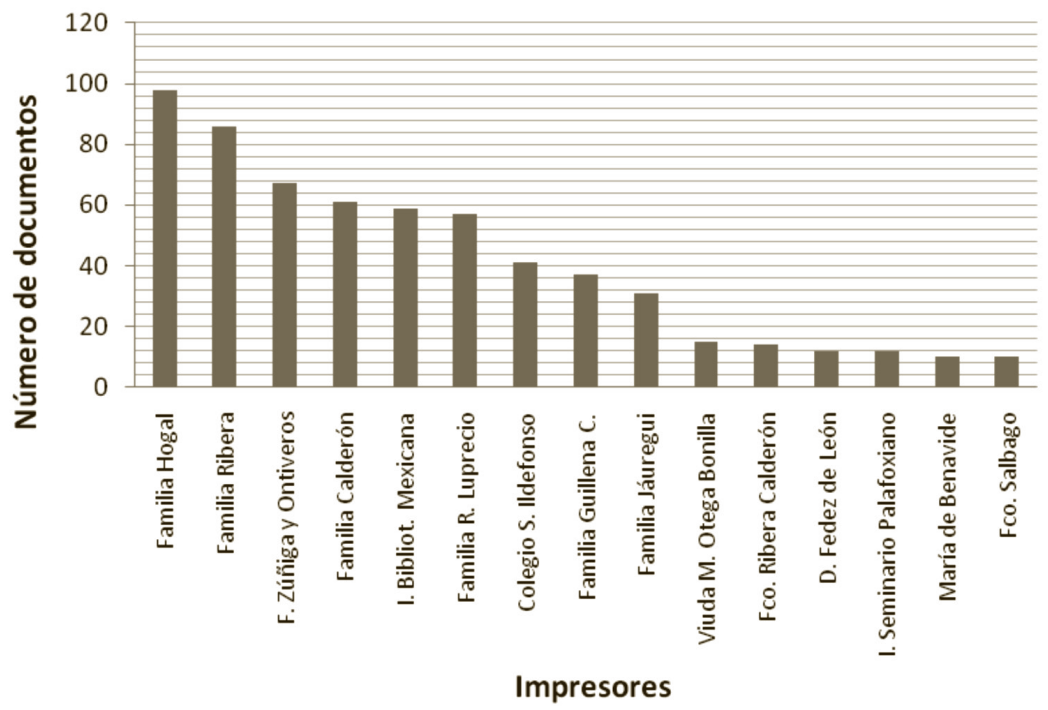


comprobar que hay dos impresores que presentan obras en dos siglos: es el caso de Francisco Rodríguez Lupercio, que aunque prácticamente toda su producción es del XVII, existe en el CCPBE una obra suya del XVIII. Algo parecido ocurre con Diego Fernández de León quien tiene dos obras del XVIII.

\subsection{Distribución de los documentos por lugares de impresión}

Siglo XVI:

- Todos publicados en México.

Siglo XVII:

- México: 268 documentos.

- Puebla de los Ángeles: 21 documentos.

- Chiapa?: 1 documento.

Siglo XVIII:

- México: 556 documentos.

- Puebla de los Ángeles: 48 documentos.

- Antequera: 4 documentos.

- San Luis de Potosí?: 2 documentos.

- Guadalajara: 1 documento.

- San Miguel del Milagro?: 1 documento.

- Tlatzcantlan?: 1 documento.

- Veracruz: 1 documento.

- Zaqualpom?: 1 documento.

Los datos referentes a los lugares de impresión nos indican que la ciudad de México, cuna de la imprenta en América, tiene un gran protagonismo a lo largo de esos tres siglos y que a partir del siglo XVII, tímidamente, van surgiendo otros focos, sobre todo en la ciudad de Puebla de los Ángeles (Angelópolis, en su denominación latina como aparece en algunas portadas). Según plantea Fernández (1977) fue la tercera ciudad americana que tuvo imprenta, pero su producción tipográfica no será muy abundante y alcanzará su mayor desarrollo en 1702 con el funcionamiento simultáneo de 4 prensas: la de Fernández de León, la de los herederos de Villareal, la de José Pérez y la de Miguel de Ortega y Bonilla. La cronología del inicio de la imprenta en Puebla no está bien definida. Según la citada autora sólo se conoce el nombre 
de la primera publicación: el Arco Triunfal o los Emblemas y Geroglificos, impresa entre 1638 y 1640 . Se tiene, en cambio, información precisa a partir de 1642.

La imprenta en Puebla de los Ángeles puede considerarse una especie de sucursal de las imprentas establecidas en la capital de la Nueva España. Sáenz de Santamaría (1990), citando a Medina (1909), indica que se conocen 227 libros impresos en el siglo XVII, que al distribuirlos por los 60 años aproximados que duró la actividad impresora en esta ciudad traen como resultado una media de 4 anuales (frente a la más de 18 al año de México).

\subsection{Distribución de los documentos por materias}

Siglo XVI

- Religión y Teología: 18 documentos (destacan: 5 catecismos, 3 sacramentos, 2 sermones, 2 liturgia procesiones).

- Lengua (vocabularios): 4 documentos.

- Derecho (leyes, provisiones): 2 documentos.

- Filosofía: 2 documentos.

- Cartas manuscritas: 2 documentos.

- Astronomía: 1 documento.

- Comercio: 1 documento.

- Geografía: 1 documento.

- Guerra: 1 documento.

- Medicina: 1 documento.

- Náutica: 1 documento.

Estos datos corroboran que la mayoría de las publicaciones impresas en el siglo XVI servían para apoyar los trabajos misionales de los religiosos. Destacan las doctrinas, los catecismos, los sermonarios, los confesionarios, las cartillas, las artes o gramáticas y los vocabularios o diccionarios. Como ejemplo de las obras que hemos localizado en el CCPBE, citamos 4 obras del franciscano Alonso de Molina (Confessionario mayor en la lengna [sic] mexicana y castellana; Doctrina christiana, en lengua mexicana...; Aqui comiença vn vocabulario en la Lengua Castellana y Mexicana; Vocabvlario en lengva Castellana y Mexicana).

Pero en este siglo las publicaciones abarcaron también otros temas, entre los que estarían, por ejemplo, el primer libro que conocemos del impresor Pedro de Ocharte, el Cedulario de Puga, 1563 y el último de este impresor, el Tractado de medicina del Padre Farfán, 1592. Entre las publicaciones de 
las imprentas mexicanas no hay que olvidar las ediciones litúrgicas de canto, las obras de tipo científico, las tesis latinas escritas por los graduados de la Real Universidad de México, las ordenanzas reales ni los libros de negocios y de noticias (Castañeda, 2001). En el CCPBE como muestra de contenido no religioso están: Primera parte de los problemas, y secretos marauillosos de las Indias de Juan de Cárdenas; Tratado brebe [sic] de medicina y de todas las enfermedades de Agustín Farfán; o Phisica speculatio del agustino Alfonso de la Vera Cruz.

\section{Siglo XVII}

- Religión y Teología: 213 documentos (destacan: 75 sermones, 28 órdenes religiosas, 19 biografías y 13 oraciones, sobre todo, fúnebres)

- Historia: 16 documentos.

- Derecho: 9 documentos.

- Lenguas indígenas (gramáticas, vocabularios): 8 documentos.

- Poesía: 4 documentos.

- Astrología, astronomía: 3 documentos.

- Armada: 2 documentos.

- Comercio: 2 documentos.

- Lengua: 2 documentos.

- Medicina: 2 documentos.

- Política: 2 documentos.

- Química: 2 documentos.

- Ayuntamientos, informes; gobierno municipal: 2 documentos.

- Materia desconocida: 2 documentos.

- Arte: 1 documento.

- Biografías: 1 documento.

- Botánica: 1 documento.

- Cronología: 1 documento.

- Encomiendas: 1 documento.

- Fortificaciones: 1 documento.

- Genealogía: 1 documento.

- Geografía: 1 documento.

- Impuestos: 1 documento.

- Inundaciones: 1 documento.

- Mayorazgos, pleitos: 1 documento.

- Memoriales: 1 documento.

- Obras públicas: 1 documento.

- Testamentos: 1 documento.

- Universidades, estatutos: 1 documento. 
Comprobamos de nuevo cómo las obras que se imprimieron durante el siglo XVII fueron en su mayoría de temas religiosos, que lógicamente habían obtenido las aprobaciones y demás requisitos legales pertinentes según la legislación de la época; y también fueron impulsadas por los mismos propósitos que tenían en la centuria anterior. De esta temática religiosa el CCPBE cuenta, por ejemplo, con Luz y guia de los ministros evangelicos... de Baltasar del Castillo, Vida y prodigios de la venerable Madre Sor Iuana de la Cruz del franciscano Juan Carrillo, Nautica sacra y viaje prodigioso del jesuita Esteban de Aguilar y muchos sermones y oraciones fúnebres, etcétera.

Existía la prohibición de imprimir sin permiso en América libros de materias profanas y fabulosas, y por otro lado la tarea emprendida por los misioneros de enseñar la civilización europea a los naturales exigía, sobre todo en los primeros tiempos de la presencia española, que las limitadas posibilidades de los impresores se consagraran exclusivamente a este esfuerzo que consideraban primordial. Por ello, catecismos, doctrinas, cartillas, diccionarios y gramáticas de las lenguas indígenas, absorbieron casi totalmente la producción de libros impresos en América durante los siglos XVI y XVII (Martínez Leal, 2002).

Pero también es cierto que al aumentar el volumen de la producción van teniendo cabida otras materias, los objetivos pedagógicos iniciales se van consiguiendo y esta necesidad es menos acuciante aunque sigue como objetivo prioritario. De ahí que en el listado anterior, las gramáticas y vocabularios en lenguas indígenas estén bien representadas (Arte de la lengua tagala de Agustin de la Magdalena, Arte de la lengua maya de Gabriel de San Buenaventura, Arte de lengua mexicana... de Agustín de Betancourt, etcétera).

Por otro lado, la implantación y desarrollo de la vida urbana, su gobierno, etc. trae consigo nuevas costumbres y demandas. Y así el CCPBE refleja que ahora se redactan narraciones históricas (Historia de la provincia de San Nicolas de Tolentino de Michoacan... de Diego Basalenque, Teatro mexicano: descripcion breve de los sucessos exemplares, historicos,... de Agustín de Betancourt, etc.), libros de Derecho (Reglas ciertas y precisamente necessarias para inezes y ministros... de Jerónimo Moreno, Sumarios de la Recopilacion general de las leyes, ordenanças, provisiones,..), de Astrología (Pronostico y lunario para el año de 1636... de Salvador Arias, etc.), o de Poesía (Grandeza mexicana de Bernardo de Balbuena, etcétera).

\section{Siglo XVIII}

- Religión y Teología: 441 documentos (sobre todo: 119 sermones, 87 oraciones —-fundamentalmente oraciones fúnebres—, 53 relacionadas 
con las diócesis — cartas pastorales, concilios—, 32 órdenes religiosas, 27 biografías, 24 devociones, 12 sacramentos, 10 catecismos).

- Derecho: 57 documentos.

- Lenguas indígenas: 12 documentos.

- Poesía: 10 documentos.

- Historia: 6 documentos.

- Geografía: 6 documentos.

El siglo XVIII mantiene las mismas tendencias que el siglo XVII, pero se afianza lentamente la diversidad temática. Ejemplos representativos de obras de materia no religiosa, tenemos en el CCPBE:

Obras jurídicas: Elucidationes ad quatuor libros institutionum Imperatoris Iustiniani..., de Jacobo Magro; o Recopilación sumaria de todos los autos acordados de la Real Audiencia y Sala del Crimen de esta Nueva España de Eusebio Ventura Beleña. Lenguas indígenas: Arte de la lengua mexicana de José Agustín Aldáma Guevara; Reglas de orthografia, diccionario y arte del idioma othomi de Luis de Neve y Molina; o Tagalysmo elucidado, y reducido (en lo possible) á la Latinidad de Nebrija... de Melchor Oyanguren de Santa Inés. Poesía: Traducción de las obras de... Publio Virgilio Maron a metro castellano, edición de Herederos de José de Jáuregui; o Amorose contienda de Francia, Italia y España sobre la Augusta persona de el Señor Don Carlos III... de Manuel Beye Cisneros. Historia: Tardes americanas: gobierno gentil y catolico: breve y particular noticia de toda la historia indiana... de José Joaquín Granados y Gálvez. Geografía: Theatro americano... de José Antonio de Villa-Señor y Sánchez; o Descripcion breve de la... ciudad de Zacatecas de José Rivera Santiago de la Laguna, Conde de Bernárdez.

En la Figura 5 se muestran conjuntamente las materias generales mejor representadas durante los tres siglos (XVI al XVII) según nos indican las obras recopiladas. Cómo es lógico, destaca en primer lugar la Religión y la Teología con 672 documentos (en la Figura 6, se indican los contenidos más destacados de estas materias). Le siguen Derecho (68 documentos), Historia (22 documentos), Lenguas indígenas (20 documentos), Poesía (14 documentos), Geografía (8 documentos), Otras lenguas (6 documentos), Astronomía (4 documentos) y Medicina (3 documentos). 


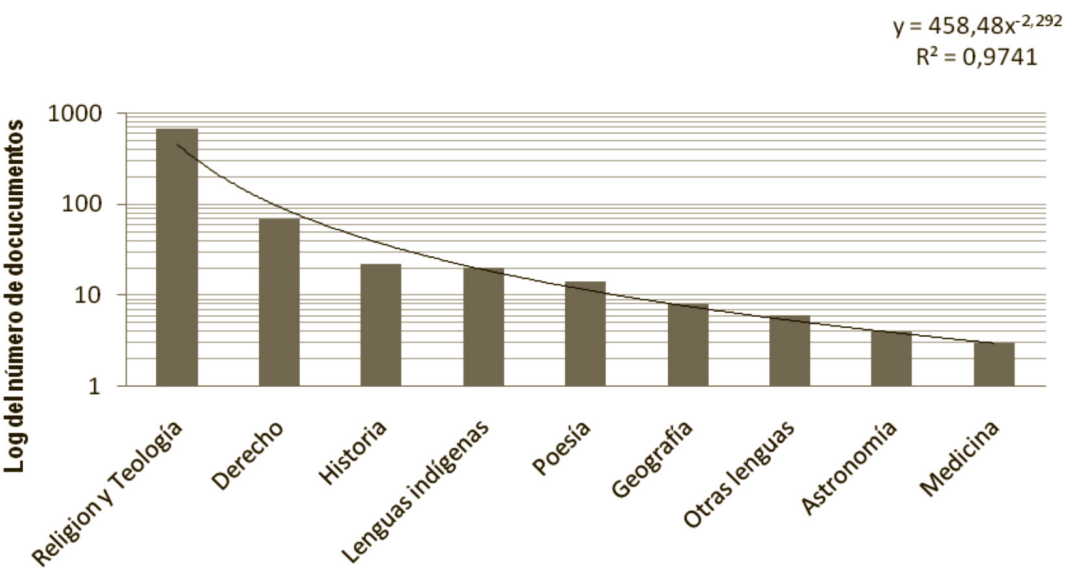

Materia

Fig. 5: Materias generales (siglos XVI-XVIII) mejor representadas

$$
\begin{gathered}
Y=231,59 x^{-1,244} \\
R^{2}=0,9364
\end{gathered}
$$

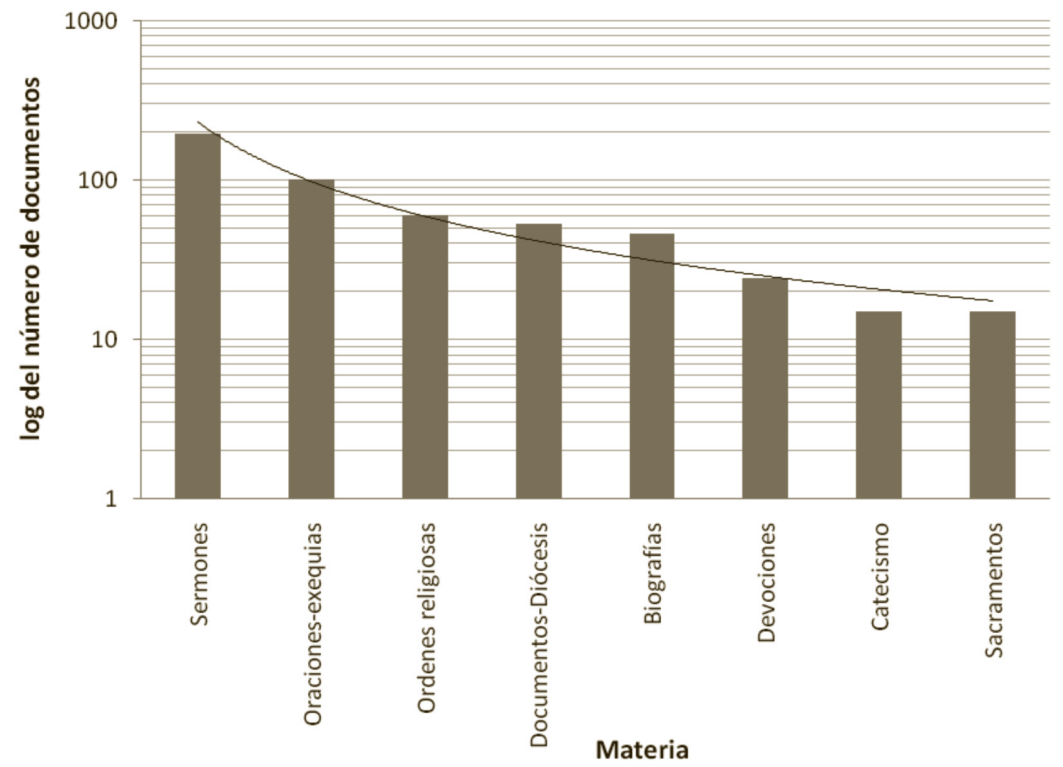

Fig. 6: Religión y Teología: contenidos destacados (siglos XVI-XVIII)

\subsection{Distribución de los documentos por idiomas}

Para la distribución de los documentos por idiomas diferenciamos, además de las lenguas europeas del momento (castellano, latín, etc.) y de las lenguas 
indígenas, los documentos impresos en varios idiomas (bilingües) y las publicaciones para aprender o explicar una lengua del tipo "Arte de la lengua...".

\section{Siglo XVI}

- Castellano: 25 documentos.

- Latín: 6 documentos.

- Lenguas indígenas: 3 documentos (lengua mexicana).

- Bilingües: 7 documentos (5 mexicano-español, 1 zapoteca-español, 1 latín-español).

Siglo XVII

- Castellano: 262 documentos.

- Latín: 14 documentos.

- Lenguas indígenas: 3 documentos (lengua mexicana).

- Bilingües: 4 documentos (1 latín-español, 2 español-mexicano, 1 timiguana-español).

- Arte de la lengua...:5 documentos (1 lengua tagala, 1 lengua maya, 3 lengua mexicana).

Siglo XVIII

- Castellano:560 documentos.

- Latín: 44 documentos.

- Leguas indígenas: 4 documentos (2 lengua mexicana, 1 lengua mixe, 1 lengua zapoteca).

- Bilingües: 2 documentos (español-mexicano).

- Arte de la lengua...: 7 documentos (5 lengua mexicana, 1 lengua tarasca, 1 lengua totonaca).

Las lenguas de publicación tienen una fácil explicación, una vez aclarado el origen y finalidad de la imprenta en México: el empleo del castellano se comprende por ser el idioma de la población urbana y ligada a la impresión de libros; el latín por la importancia de las órdenes religiosas, la Iglesia y el predominio de la temática religiosa en los impresos; y las lenguas indígenas porque como explica Lafaye (2002):

Los pioneros de la evangelización se lanzaron a una intensa labor de aprendizaje de las lenguas indígenas que eran regionalmente numerosas. Lograron en pocos 
años resultados extraordinarios elaborando diccionarios bilingües y gramáticas, catecismos en lenguas indígenas y hasta en jeroglíficos. Aquella hazaña filológica se hubiera quedado in vitro y estéril sin el socorro de la imprenta. Ningún cajista de la Península conocía este idioma; mandar pruebas por barco suponía mucho tiempo....

En este mismo sentido Fernández (1999) mantiene que los misioneros tuvieron muy claras las dificultades de idioma a las que tenían que hacer frente, y que lo más fácil era conocer las lenguas indígenas para así poderles enseñar español; el paso siguiente: establecer centros educativos junto a los monasterios. De todos modos los españoles también se enriquecieron aprendiendo las lenguas y con ellas las tradiciones y costumbres.

\subsection{Distribución de los documentos por número de ejemplares conservados $y$ por bibliotecas}

Siglo XVI

- De 26 documentos se conserva 1 ejemplar.

- De 7 documentos se conservan 2 ejemplares.

- De 1 documento se conservan 3 ejemplares.

Las bibliotecas en las que se guardan estos documentos son las siguientes:

- Biblioteca Nacional: 19 ejemplares.

- Biblioteca, Universidad de Salamanca: 10 ejemplares.

- Biblioteca Hispánica (Instituto de Cooperación Iberoamericana, Agencia Española de Cooperación Internacional para el Desarrollo): 4 ejemplares.

- Biblioteca, Real Academia de la Historia: 3 ejemplares.

- Biblioteca colombina: 2 ejemplares.

- Biblioteca Pública del Estado en Córdoba: 1 ejemplar.

- Biblioteca Pública del Estado en Cádiz: 1 ejemplar.

- Biblioteca, Museo Naval de Madrid: 1 ejemplar.

- Biblioteca, Catedral de Burgo de Osma: 1 ejemplar.

- Biblioteca privada, País Vasco (sin permiso para difundir la identidad): 1 documento. 
Siglo XVII

- De 208 documentos se conserva 1 ejemplar.

- De 43 documentos se conservan 2 ejemplares.

- De 15 documentos se conservan 3 ejemplares.

- De 6 documentos se conservan 4 ejemplares.

- De 4 documentos se conservan 5 ejemplares.

- De 1 documento se conservan 6 ejemplares.

- De 4 documentos se conservan 8 ejemplares.

- De 2 documentos se conservan 9 ejemplares.

- De 1 documento se conservan 11 ejemplares.

- De 1 documento se conservan 12 ejemplares.

- De 1 documento se conservan17 ejemplares.

- De 1 documento se conservan 21 ejemplares.

Del notable número de bibliotecas diferentes que son depositarias de estos documentos, más de 30 destacan por conservar al menos 10 ejemplares, las que indicamos a continuación:

- Biblioteca Nacional: 120 ejemplares.

- Biblioteca, Real Academia de la Historia: 51 ejemplares.

- Biblioteca de Castilla-La Mancha: 33 ejemplares.

- Biblioteca Pública del Estado en Huesca: 28 ejemplares.

- Biblioteca Hispánica (Instituto de Cooperación Iberoamericana, Agencia Española de Cooperación Internacional para el Desarrollo): 27 ejemplares.

- Biblioteca, Universidad de Granada: 17 ejemplares.

- Biblioteca, Universidad de Sevilla: 14 ejemplares.

- Biblioteca, Universidad Complutense: 13 ejemplares.

- Biblioteca Pública del Estado en Palma de Mallorca: 12 ejemplares.

- Biblioteca Pública del Estado en Cádiz: 11 ejemplares.

- Biblioteca, Instituto Teológico Compostelano: 10 ejemplares.

- Biblioteca, Universidad de Valencia: 10 ejemplares.

Siglo XVIII

- De 470 documentos se conserva 1 ejemplar.

- De 90 documentos se conservan 2 ejemplares.

- De 17 documentos se conservan 3 ejemplares.

- De 19 documentos se conservan 4 ejemplares. 
- De 6 documentos se conservan 5 ejemplares.

- De 4 documentos se conservan 6 ejemplares.

- De 3 documentos se conservan 7 ejemplares.

- De 1 documento se conservan 9 ejemplares.

- De 2 documentos se conservan 10 ejemplares.

- De 1 documento se conservan 26 ejemplares.

- De 1 documento se conservan 31 ejemplares.

- De 1 documento se conservan 40 ejemplares.

- De 1 documento se conservan 51 ejemplares.

- De 1 documento se conservan 78 ejemplares.

Del destacado número de bibliotecas diferentes en las que podemos consultar estos documentos (más de 40 bibliotecas), destacan por conservar al menos 10 ejemplares, las que indicamos a continuación:

- Biblioteca de Castilla-La Mancha: 206 ejemplares.

- Biblioteca Hispánica (Instituto de Cooperación Iberoamericana, Agencia Española de Cooperación Internacional para el Desarrollo): 96 ejemplares.

- Biblioteca Pública del Estado en Huesca: 96 ejemplares.

- Biblioteca Pública del Estado en Cádiz: 83 ejemplares.

- Biblioteca, Real Academia de la Historia: 83 ejemplares.

- Biblioteca, Seminario de Cuenca: 30 ejemplares.

- Biblioteca, Seminario de Barcelona: 19 ejemplares.

- Biblioteca, Universidad de Sevilla: 18 ejemplares.

- Biblioteca, Universidad de Comillas, Cantoblanco, Madrid: 17 ejemplares.

- Biblioteca, Universidad Complutense: 16 ejemplares.

- Biblioteca Nacional: 14 ejemplares.

- Biblioteca, Facultad de Teología, Granada: 14 ejemplares.

- Biblioteca, Facultad de Teología San Vicente Ferrer, Valencia): 12 ejemplares.

En conjunto, para el periodo estudiado destacan claramente 5 bibliotecas: la Biblioteca de Castilla-La Mancha, La Biblioteca Hispánica (AECID), La Biblioteca Nacional, la Biblioteca Pública del Estado en Huesca y la Biblioteca de la Real Academia de la Historia. Pero la Biblioteca Nacional deja de tener protagonismo para los fondos del siglo XVIII, en el que alcanzan un puesto más destacado la Biblioteca Pública de Huesca o la de Cádiz. También nos damos cuenta que para el siglo XVI la Biblioteca de la Universidad 
de Salamanca ocupa el segundo lugar, mientras que para los otros dos siglos no hemos localizado información sobre ejemplares que hagan referencia a esta Biblioteca.

Describimos brevemente el origen de estas importantes colecciones de fondos antiguos, información que nos ayuda a comprender los datos anteriores: ${ }^{12}$

- Biblioteca de Castilla-La Mancha <http://pagina.jccm.es/biblioclm/>: su origen se remonta a los años 70 del siglo XVIII, cuando el Cardenal Lorenzana abrió al público la Biblioteca Arzobispal por indicación del rey Carlos III. En el siglo XIX el Estado cambió la titularidad de los fondos, que pasarán a constituir la base de la Biblioteca Provincial. Su evolución continúa en el siglo XX y se consolida también su función de biblioteca pública. En la actualidad en su ubicación del Alcázar de Toledo es la Biblioteca Regional de la Comunidad Autónoma de Castilla-La Mancha y la Biblioteca Pública del Estado en Toledo. De todas las colecciones que la forman, la Colección Borbón-Lorenzana es la de mayor antigüedad y valor bibliográfico con los fondos del citado Cardenal, y reúne el patrimonio de sus antecesores en el arzobispado, los libros valiosos y objetos curiosos que él mismo trajo de su estancia en Méjico (y con los que conformaría un Gabinete de Historia Natural) y los más de 9000 libros propiedad del colegio de Jesuitas. Dicha colección se enriqueció en 1794 con los libros del futuro cardenal Luis María de Borbón. La colección está compuesta por unos 700 manuscritos, 414 incunables y más de 100.000 libros impresos entre los siglos XVI y XIX.

- Biblioteca Hispánica (AECID) <http://194.140.3.20/web/es/bibliotecas />: es uno de los centros de información especializada más importantes de Europa que se forma como colección bibliográfica del Consejo de la Hispanidad, cuya finalidad consistía en conservar y fomentar la herencia hispánica en los países de América y Filipinas; por este motivo el tema central de la primera colección histórica consiste en la literatura del descubrimiento, los Reyes Católicos y la evangelización de América.

- Biblioteca Nacional <http://www.bne.es>: institución bibliotecaria superior del Estado y cabecera del Sistema Bibliotecario Español, fundada por el rey Felipe $\mathrm{V}$ a finales de 1711. Se inaugura al público un año más tarde como Real Biblioteca Pública. Por un privilegio real los 
impresores debían depositar ahí un ejemplar de los libros impresos en España. El nombre de Biblioteca Nacional se remonta a 1836 cuando pasa a depender del Ministerio de la Gobernación. En su origen real se fundamenta la procedencia de las colecciones más antiguas, cuyo núcleo inicial estaba integrado por los libros de la Torre Alta del Real Alcázar, los libros que Felipe V trajo desde Francia y los que se iban a incautar a los partidarios del Archiduque de Austria en la Guerra de Sucesión. En este núcleo inicial encontramos ya algunas de las piezas fundamentales de la colección que continuaría incrementándose con importantes adquisiciones en el siglo XVIII y sobre todo en el siglo XIX. El incremento más significativo se iba a producir en el siglo XIX por la incorporación de los conventos suprimidos por la desamortización y por la adquisición de bibliotecas particulares que ingresan por compra o legado o bien se reciben en la Biblioteca Nacional procedentes de otros Ministerios en los que se habían depositado previamente.

- Biblioteca de la Real Academia de la Historia <http://www.rah.es/>: la Real Academia de la Historia posee una biblioteca indispensable para el estudio e investigación de la historia de España y de la América hispánica: libros, folletos impresos, códices y documentación manuscrita desde la alta Edad Media hasta la actualidad. El fondo impreso de la Biblioteca consta actualmente de más de 400.000 volúmenes, entre ellos 200 incunables. La mayor parte de las colecciones contienen los trabajos de investigación de los propios académicos y otros historiadores de los siglos XVIII, XIX y primera mitad del XX. Hay varias colecciones especialmente importantes para la historia de América, como la formada por don Juan Bautista Muñoz, comisionado por Carlos III para escribir una historia de América y fundador del Archivo General de Indias. La colección ingresó en la Academia en 1818; o las colecciones relativas a la historia y actividades de la Compañía de Jesús en España y en las misiones ultramarinas entre los siglos XVI y XVIII: la llamada Biblioteca de Cortes y la colección Jesuitas.

- Biblioteca Pública del Estado en Huesca <http://www.bibliotecaspublicas.es/b-huesca/informacion.htm>: se fundó en 1845, al suprimirse la Universidad Sertoriana, recogiendo los libros procedentes de este organismo y de sus Colegios Mayores de San Vicente y Santiago. Tenía su sede en el edificio de la Universidad, antes Palacio de los Reyes de Aragón y hoy Museo Provincial de Bellas Artes, convertido por aquellas fechas en Instituto de Segunda Enseñanza. En 1870 ingresaron en la Biblioteca cerca de 2.500 volúmenes procedentes de los 
monasterios desamortizados de Roda de Isábena, San Victorián y San Juan de la Peña. Estos libros, con los de la Universidad, constituyen el fondo antiguo de la Biblioteca que alcanza los 25.000 volúmenes.

- Biblioteca Pública del Estado en Cádiz <www.juntadeandalucia.es/cultura/bibliotecas/bpcadiz >: en la actualidad es una biblioteca de titularidad estatal y gestionada por la Junta de Andalucía, se remonta a 1851, año en el que abre sus puertas en con un fondo inicial de unos 12.000 volúmenes procedentes en su mayor parte de las bibliotecas de los conventos desamortizados de los Capuchinos, San Francisco y San Agustín.

- Biblioteca General Histórica de la Universidad de Salamanca <http:// campus.usal.es/ bgh/1024/html/index2.htm>: esta Universidad surge como Estudio salmantino y posteriormente pasa a Universidad de Salamanca; se funda en 1218 por voluntad del rey Alfonso IX de León. Pero será en 1254 cuando empieza a funcionar. En 1255, el Papa Alejandro IV concedió validez universal a los títulos impartidos por la nueva Universidad y le permitió el uso de un sello propio. 1254 se considera también el año del inicio de la Biblioteca Universitaria, pues la Carta Magna de Alfonso X recogía la creación del cargo de Estacionario o propietario de una "Estación" de libros, retribuido por la Universidad y encargado de mantener ejemplares actualizados para la consulta. Su primer esplendor se alcanza en la segunda mitad del siglo $\mathrm{XV}$ y durante todo el siglo XVI.

\section{Conclusiones}

La principal aportación de este trabajo ha consistido en aplicar las herramientas cuantitativas al estudio de un gran catálogo colectivo de libros antiguos: el CCPBE y utilizar otro gran catálogo (el de Fondos antiguos de México) como término de comparación para señalar la mayor o menor singularidad de los fondos analizados. La riqueza de datos e información que agrupan estos catálogos son una fuente interesante para aplicar las técnicas cuantitativas, pues están diseñadas para tratar y gestionar gran cantidad de datos y facilitar su presentación e interpretación.

Los trabajos realizados con anterioridad, cercanos a los objetivos que nos hemos propuesto, no son muy abundantes. Como ejemplo más próximo citamos el realizado por Herrero (1997), que recoge en el título la expresión "análisis documental y bibliométrico". El trabajo se centra en el diseño y elaboración de una base de datos para describir una colección de libros antiguos del siglo XVI. 
Existen también otras investigaciones sobre fondos antiguos de bibliotecas españolas; de éstos los que consideramos más próximos a este trabajo son dos artículos en los que participamos los autores de esta investigación, que tienen por objeto de estudio el fondo antiguo de la biblioteca de la Sociedad Económica Extremeña de Amigos del País (Pulgarín, Herrera y Marroquín, 2007 y 2009), y algunos estudios de carácter histórico, por ejemplo, sobre bibliotecas ya desaparecidas a partir de documentos conservados. Es el caso del trabajo de Vivas (2000) que analiza la biblioteca del convento de los dominicos de San Esteban de Salamanca a través de un manuscrito. En otros, los autores se limitan a reconstruir el índice o inventario de los libros, con más o menos detalle (Galende, 2000; Varela, 1999) -en algún caso se aprovecha para analizar los gustos sobre lecturas (San Martín, 1996). Conocemos algún estudio bibliométrico para obras del XVIII, que se centra en el análisis de la producción científica de una determinada materia; es el caso del trabajo de Sáez y Marset (1993) en el que analizan la producción científica de Medicina en Murcia en el siglo XVIII.

También hemos comprobado que el CCPBE da información sobre una buena muestra de obras mexicanas publicadas en los siglos XVI al XVIII: 939 documentos (521 libros, 413 folletos, 3 hojas sueltas, y 2 manuscritos), de los cuales 676 no están recogidos, por ahora, en el Catálogo de Fondos antiguos de México y 263 documentos sí están registrados (241 libros y 22 folletos). Estas cifras nos indican que la diferencia es mayor para los folletos que para los libros. Sobre estos catálogos debemos tener presente que son recursos que siguen completándose con nuevos registros y que el catálogo español se inició hace más tiempo y por tanto está más desarrollado. De todos modos, estos datos comparativos son bastante significativos para destacar la importante colección de libros mexicanos conservados en España y su valor bibliográfico, a la que hay que añadir los 2.491 documentos del siglo XIX que pretendemos seguir analizando en otro trabajo posterior.

Por otro lado cabe destacar la notable cantidad y variedad de bibliotecas españolas que conservan obras impresas en México durante estos siglos. Estos datos corroboran lo afirmado por Fernández de Zamora (2004 y 2009) en sus trabajos sobre los impresos mexicanos del siglo XVI. Esta autora ha comprobado cómo muchas obras de ese siglo se conservan fuera de México, en bibliotecas extranjeras, sobre lo que expone dos posibles causas: "1. La nacionalización de los bienes del clero y el poco aprecio de los liberales por el legado cultural novohispano. 2. El resurgimiento de la bibliofilia en el siglo XIX".

Con esta investigación queremos contribuir a la difusión de los impresos localizados. Este estudio puede ser un instrumento para completar la producción 
tipográfica mexicana mediante la digitalización de las obras originales que están en España y no las posee ninguna biblioteca mexicana.

Finalmente consideramos que la aplicación de las técnicas cuantitativas ha sido de utilidad para el estudio de la muestra seleccionada del CCPBE, las proponemos como una gran ayuda para dar una visión de conjunto, sintética y a la vez detallada, y que facilita una descripción muy adecuada para difundir las características esenciales del fondo. A la vez son un apoyo para facilitar la evaluación y comparación de la muestra seleccionada.

\section{Referencias Bibliográficas}

Andrade, Vicente de P. (1899), Ensayo bibliográfico mexicano del siglo XVII, $2^{a}$ ed. México: Imprenta del Museo Nacional.

Brito Ocampo, Sofía (2010), El catálogo Colectivo de Fondos Antiguos, Patrimonio Bibliográfico Mexicano: una herramienta necesaria [en línea], [consulta: 26 junio 2010], disponible en: biblional.bibliog. unam.mx/iib/difusion/ccfapccfa.doc

Castañeda, Carmen (2001), Libros en la Nueva España en el siglo XVI, en Peña Díaz, Manuel; Ruiz Pérez, Pedro; Solana Pujalte, Julián, La cultura del libro en la edad moderna: Andalucía y América. Córdoba: Servicio de Publicaciones de la Universidad de Córdoba, pp. 271-288.

Fernández, Stella Maris (1999), Hispanoamérica; su registro cultural a través de la imprenta, comunicación presentada en la 65th IFLA Council and General Conference Bangkok,Thailand, August 20 August 28, 1999, [en línea], [consulta: 23 junio 2010], disponible en: http://archive.ifla.org/IV/ifla65/papers/111-137s.htm

, (1977), La Imprenta en Hispanoamérica, Madrid: ANABA.

, (2001), "El libro en Hispanoamérica", en Escolar Sobri-

no, Hipólito. Historia ilustrada del libro español. De los incunables al siglo XVIII, Madrid: Fundación Germán Sánchez Ruipérez, pp. 447-497.

(2004), "Presencia de los impresos mexicanos del Siglo XVI en las bibliotecas del siglo XXI", en Investigación Bibliotecológica, vol. 18, núm 36, enero-junio, pp.7-26, también disponible en: http://132.248.242.3/ publica/archivos/36/ibi03602.pdf

Fernández de Zamora, Rosa María (2009), Los impresos mexicanos del siglo XVI, su presencia en el patrimonio cultural del nuevo siglo, México: Universidad Nacional Autónoma de México.

Galende Díaz, Juan Carlos (2000), "La biblioteca del colegio mayor salmantino de San Bartolomé en el siglo XVIII", en Revista General de Información y Documentación, vol. 10, núm 2, pp. 33-69.

García Icazbalceta, Joaquín (1954), Bibliografía mexicana del siglo XVI, Nueva edición por Agustín Millares Carlo, México: FCE. 
Griffin, Clive (1991), Los Cromberger: la bistoria de una imprenta del siglo XVI en Sevilla y México, Madrid: Cultura Hispánica.

Herrero Pascual, Cristina (1997), "Análisis documental y bibliométrico de los libros del siglo XVI de la Biblioteca de los Obispos (Murcia)", en Revista General de Información y Documentación, vol. 7, núm 2, pp. 141-166.

Lafaye, Jacques (2002), Albores de la Imprenta. El libro en España y Portugal y sus posesiones de utltramar (siglos XV-XVI), México: Fondo de Cultura Económica.

Leonard, Irving A. (1979), Los libros del conquistador, $2^{a}$ ed. México, D.F.: Fondo de Cultura Económica.

Lucena Salmoral, Manuel (1990), La cultura, en Historial General de España y América. El descubrimiento y la fundación de los reinos ultramarinos hasta finales del siglo XVI, Tomo VII. $2^{\text {a }}$ ed. Madrid: Ediciones Rialp, pp. 741-766.

Martínez, José Luis (1987), El libro en Hispanoamérica: origen y desarrollo, $3^{a}$ ed. Salamanca: Fundación Germán Sánchez Ruipérez.

Martínez Leal, Luisa (2002). Los impresores libreros en Nueva España del siglo XVII, [en línea], disponible en: http://www.difusioncultural.uam.mx/revista/may2002/martinez.pdf

Medina, José Toribio (1909), La Imprenta en México (1539-1821), Santiago de Chile: Impreso en casa del autor.

Mora Mérida, José Luis (1990), La Cultura, en Historial General de España y América. América en el siglo XVIII. Los primeros Borbones, Tomo XI-1, $2^{a}$ ed. Madrid: Ediciones Rialp, pp. 327-345.

Pulgarín Guerrero, Antonio; Herrera Morillas, José Luis; Marroquín Martínez, Laura (2007), "Estudio bibliométrico de la biblioteca de la Real Sociedad Económica Extremeña de Amigos del País. Parte I, colección de los siglos XVI-XVIII", en Revista general de información y documentación, vol. 17, núm 2, pp. 186-208.

Pulgarín Guerrero, Antonio; Herrera Morillas, José Luis; Marroquín Martínez, Laura (2009), "Estudio bibliométrico de la biblioteca de la Real Sociedad Económica Extremeña de amigos del país. Parte II. Colección del siglo XIX”, en Revista general de información y documentación, vol. 19, núm 1, pp. 91-119.

Reyes Gómez, Fermín de los (2003), Introducción, en Pedraza Gracia, Manuel José; Clemente San Román, Yolanda; Reyes Gómez, Fermín de los: El libro antiguo, Madrid: Síntesis, pp. 11-48.

Sáez Gómez, José Miguel; Marset Campos, Pedro (1993), "La producción científico-médica murciana en el siglo XVIII", Llull. Boletín de la Sociedad Española de Historia de las Ciencias, vol. 16, núm 31, pp. 537-548.

Sáenz de Santa María Ortiz de Uriarte, Carmelo (1990), El despliegue cultural en el siglo XVII, en Historial General de España y América. América en el siglo XVII. Los problemas generales, Tomo IX-1. 2a ed. Madrid: Ediciones Rialp, pp. 361-369. 
San Martín Casi, Roberto (1996), "Notas sobre una biblioteca sacerdotal tafallesa del s. XVIII", en Revista TK, vol. 2, diciembre, pp. 59-68.

Varela Orol, Concha (1999), "Las bibliothecas de la biblioteca universitaria de Santiago en el siglo XVIII", en III Jornadas de Arquivos, Bibliotecas, Centros de documentación E Museos de Galicia: As Novas Tecnoloxias O Servicio Do Usuario, Santiago de Compostela: Xunta de Galicia, pp. 513-520.

Velasco de la Peña, Esperanza; Merlo Vega, José Antonio (2000), Nuevas formas para el acceso al libro antiguo [en línea], [consulta: 23 junio 2010], disponible en: http://exlibris.usal.es/merlo/escritos/pdf/aib.pdf

Vivas Moreno, Agustín (2000), "La biblioteca del convento de los dominicos de San Esteban de Salamanca en el siglo XVIII", en Revista General de Información y Documentación, vol. 10, núm 2, pp. 71103. 